\title{
Glossa
}

a journal of general linguistics

\section{Resolving ambiguous polarity stripping ellipsis structures in Persian}

\section{RESEARCH}

\section{VAHIDEH RASEKHI (D)}

JESSE A. HARRIS (D)

*Author affiliations can be found in the back matter of this article

\begin{abstract}
Previous studies have shown that English speakers use a range of factors including locality, information structure, and semantic parallelism to interpret clausal ellipsis structures. Yet, the relative importance of each factor is currently underexplored. As cues to information structure and semantic parallelism are often implicit in English, we turned to Persian which marks information structure overtly via word order scrambling and uses the -rā morpheme to indicate definiteness/specificity on direct objects. To determine what strategies Persian speakers use to disambiguate clausal ellipsis, we conducted a naturalness rating study and sentence completion task on polarity stripping structures. Our results show that information structure and parallelism strongly influence correlate resolution in both tasks, but that a weaker preference for a local correlate emerges in scrambling in the sentence completion task. As these results diverge from those obtained in English studies, we speculate that the morphosyntactic properties of Persian constrain the strategies the processer uses in selecting a contrastive correlate and resolving ambiguity in stripping ellipsis.
\end{abstract}

\section{CORRESPONDING AUTHOR:}

\section{Vahideh Rasekhi}

University of California, Los Angeles, 3125 Campbell Hall, Los Angeles, CA 90095 vrasekhi@gmail.com

\section{KEYWORDS:}

Stripping ellipsis in Persian; Ambiguity resolution; Parallelism; Locality; Information structure

TO CITE THIS ARTICLE: Rasekhi, Vahideh and Jesse A. Harris. 2021. Resolving ambiguous polarity stripping ellipsis structures in Persian. Glossa: a journal of general linguistics 6(1): 120. 1-31. DOI: https://doi.org/10.16995/ glossa.5881 


\section{Introduction}

Ellipsis refers to a well-studied phenomenon in which one or more elements are elided from the sentence, but nevertheless contribute to sentence meaning. While the exact licensing conditions for ellipsis are still under debate (see Merchant 2019 for discussion and references), ellipsis generally requires a salient linguistic antecedent which can be recovered from the context (Hankamer \& Sag 1976). Although ellipsis takes many forms, we focus here on cases of clausal ellipsis known as stripping (Ross 1969; Hankamer \& Sag 1976), sometimes also called bare argument ellipsis (1). ${ }^{1}$ In the case of (1a), the remnant (a magazine) is interpreted with respect to the elided content $\Delta,{ }^{2}$ along the lines of (1b), contrasting with the correlate (a book) in the antecedent clause. ${ }^{3}$

a. Mary bought $\left[_{\text {Correlate }}\right.$ a book], (but) not $\left[_{\text {Remnant }}\right.$ a magazine $] \Delta$.

b. Mary bought a book, (but) she did not buy a magazine.

The apparent mismatch between form and meaning poses a series of recalcitrant and complex challenges in the theoretical literature on ellipsis. Central issues include whether elided material $\Delta$ is syntactically present, yet unpronounced, at some level of representation, how closely the elided material needs to match the antecedent and on what dimensions, and the conditions under which ellipsis is licensed in particular constructions (e.g., Keenan 1971; Sag 1976; Sag \& Hankamer 1984; Hardt 1993; Fiengo \& May 1994; Chung et al. 1995; Fox 2000; Merchant 2001, 2013; Culicover \& Jackendoff 2005; Chung 2013). These questions, and others, have occupied a central place in core syntactic theory for more than 40 years.

A closely-related literature in experimental syntax and psycholinguistics has also emerged, addressing a parallel set of issues. Central issues in this literature include how ellipsis structures are incrementally parsed and interpreted given constraints imposed by the grammar, the extent that discourse, prosody and information structure affect how ambiguous ellipses are interpreted, and the extent to which these processes are specific to ellipsis or reflect more general principles of language processing (e.g., see Phillips \& Parker 2014; Frazier 2018; Yoshida 2018 for discussion). We focus here on a critical, yet somewhat understudied, aspect of ellipsis in sentence processing: how does the language processing system recover a correlate for the remnant in clausal ellipsis cross-linguistically?

In this paper, we explore the interpretation of ambiguous stripping ellipsis in Persian. We concentrate on Locality and Parallelism, two factors that have been found to guide clausal ellipsis resolution in English (e.g., Carlson 2001, 2002; Frazier \& Clifton 1998, 2005; Harris \& Carlson 2018). After introducing the key structural and interpretive properties of clausal ellipsis, we then review the relevant literature in sentence processing, followed by a brief overview of stripping ellipsis and definiteness marking in Persian. The results of two offline studies are presented and discussed in light of prior studies on English.

\subsection{Clausal ellipsis structures}

Clausal ellipsis is ellipsis with a clausal source in which only a single element, the remnant, is overtly expressed. Cases of sluicing (2a; Ross 1969; Merchant 2001; van Craenenbroek 2010, 2012), fragment answers (2b; Merchant 2004), and stripping ellipsis (2c; Lobeck 1995; Merchant 2003; Nakao 2009; Wurmbrand 2017) illustrate:
a. Alice met someone, but I don't know who $\Delta$.
b. Who did Alice meet? Ben $\Delta$.
c. Alice met Carol, but not Ben $\Delta$.

ta


The literature on ellipsis has spawned a wealth of approaches, which can be divided roughly into syntactic (Sag 1976; Williams 1977; Fiengo and May 1994; Chung et al. 1995; Fox 2000; among others) and non-syntactic (Sag and Hankamer 1984; Merchant 2001; van Craenenbroeck 2010; Aelbrecht 2010; among others) accounts. While our study does not crucially depend on a particular analysis, we will adopt a syntactic "move and delete" approach (Jayaseelan 2001; Merchant 2001, 2003, 2004; Depiante 2000; Ortega-Santos et al. 2014; Yoshida et al. 2015; among others), in which the remnant has moved from TP to the CP domain, before TP ellipsis takes place. ${ }^{4}$ For instance, the clausal source for the respective ellipsis structures in (2) would be spelled out roughly as (3) below. In these cases, the remnant has moved to the Spec of FocP, out of the material targeted for deletion (represented with a strikethrough):

$$
\begin{aligned}
& \text { a. Alice met someone, but I don't know }\left[{ }_{\mathrm{CP}}\left[\mathrm{FocP}_{\text {who }}\left[{ }_{\mathrm{TP}} \text { Alice met } t_{1}\right]\right]\right] \\
& \text { b. Who did Alice meet? }\left[{ }_{\mathrm{CP}}\left[{ }_{\mathrm{FocP}} \operatorname{Ben}_{1}\left[{ }_{\mathrm{TP}} \text { Alice met } t_{1}\right]\right]\right. \\
& \text { c. Alice met Carol, but }\left[\mathrm{CP}_{\mathrm{CP}} \text { not }\left[{ }_{\mathrm{FocP}} \operatorname{Ben}_{1}\left[{ }_{\mathrm{TP}} \text { Alice met } t_{1}\right]\right]\right]
\end{aligned}
$$

In languages such as German, it has been proposed that the remnant of stripping ellipsis can function as a contrastive topic (4B) or contrastive focus (4C) (Konietzko \& Winkler 2010). One of the diagnostics Konietzko and Winkler use to determine the discourse status of the remnant in stripping ellipsis is the relative placement of a sentential adverb and the remnant. In particular, contrastive topic remnants occur above (4B) but not below a sentential adverb (4B'), unlike contrastive focus remnants (4C).

$$
\begin{aligned}
& \text { A: Will both of your siblings go to France? } \\
& \text { A': Will Maria go to France? } \\
& \text { B: Maria wird wohl fahren, aber Hans vermutlich nicht (Contrastive topic } \\
& \text { ellipsis) } \\
& \text { Maria will PART go but Hans probably not } \\
& \text { Lit: 'Maria will go but Hans probably not.' } \\
& \text { B': "Maria wird wohl fahren, aber vermutlich Hans nicht } \\
& \text { Maria will PART go but probably Hans not } \\
& \text { C: Maria wird wohl nicht fahren, aber vermutlich Hans (Contrastive focus } \\
& \text { Maria will PART not go but probably Hans ellipsis) } \\
& \text { Lit: 'Maria will not go but probably Hans (will go).' }
\end{aligned}
$$

The question in (4A) asks about a set of individuals, which can then be presupposed in the context, allowing for an answer that contains contrastive topic, as in (4B). On the other hand, in (4C) as an answer to (4A'), the remnant Hans represents new information; therefore, it functions as a focalized element (see Konietzko \& Winkler 2010 for further discussion on how to differentiate topic and focus in German). In contrastive-topic ellipsis (4B), the remnant is assumed to move to TopP in the left-periphery while in contrastive-focus ellipsis (4C), the remnant is assumed to move to FocP, below the negation and sentential adverb (Konietzko \& Winkler 2010).

In this paper, we will be concerned with related cases of Polarity stripping in Persian (5), in which the negative marker na follows the remnant, and a coordinator like but introduces the elided clause in which the polarity is reversed (Toosarvandani 2013, 2014; Rasekhi 2018, 2020). ${ }^{5}$ In (5), the contrastive topic remnant moāven contrasts with a correlate in the antecedent clause (see Rasekhi 2018, 2020 for evidence). However, the correlate-remnant pairing is formally ambiguous, as the remnant could contrast with either the object (5a) or the subject (5b) of the antecedent clause.

4 Taking Merchant's (2001) account of clausal ellipsis for illustration, ellipsis takes place in two steps. First, the remnant raises out of the ellipsis site to a position above TP. Second, an [E] feature on a functional head licenses the deletion of its complement at the PF level. Following this analysis, the underlying structure of the second clause of (3a) would be as illustrated in (i). First, the wh-phrase remnant who moves from the ellipsis site (TP) to the Spec of FocP. Then the [E] feature on the Foc head licenses the deletion of its complement, TP.

(i) $\quad$...but I don't know $\left[_{\mathrm{FocP}}\right.$ who $_{\mathrm{i}}\left[_{\mathrm{Foc}[\mathrm{E}]}\left[\left[_{\mathrm{TP}}\right.\right.\right.$ Aliee $\left.\left.\left.t_{\mathrm{i}}\right]\right]\right]$

5 Stripping ellipsis is typically characterized by a negative marker, an affirmative element, or an adverb linking the elided clause with its host. In this paper, we focus on polarity stripping in Persian, in which negation occurs after the remnant (see Rasekhi 2018, 2019, 2020 for the discussion on different types of stripping ellipsis in Persian). 
modir monshi estekhdām = kard vali moāven na (estekhdām=na kard) manager secretary hire $=$ did.3SG but assistant NEG hire $=$ NEG-did.3SG

a. Object contrast: 'The manager hired a secretary but the manager did not hire an assistant.'

b. Subject contrast: 'The manager hired a secretary but the assistant did not hire a secretary.'

The underlying structure of the ellipsis for object (5a) and subject (5b) contrastive-topic remnants is assumed to be as in (6a) and (6b), respectively (see section 1.3.5. for further discussion on polarity stripping in Persian).

$$
\begin{array}{llllllll}
\text { a. } & \ldots & C_{\mathrm{CP}} & C_{\mathrm{TopP}} \text { moāven }_{\mathrm{i}} & C_{\mathrm{PolP}} \text { na } & \mathrm{C}_{\mathrm{TP}} \text { modirr } & t_{\mathrm{i}} & \text { estekhdām_nakard }] \\
\text { b. } & \ldots & \mathrm{C}_{\mathrm{CP}} & \mathrm{C}_{\mathrm{TopP}} \text { moāven }_{\mathrm{i}} & \mathrm{C}_{\mathrm{PolP}} \text { na } & \mathrm{C}_{\mathrm{TP}} t_{\mathrm{i}} & \text { monshì } & \text { estekhdām=nakard }]
\end{array}
$$

As illustrated in (6), the structure and the interpretation of the ellipsis depend on the choice of correlate-remnant pairing. An Object contrast places the remnant moāven "assistant" in object position within the ellipsis, whereas a Subject contrast places the remnant in subject position.

Correlate-remnant pairing itself appears to be sensitive to several factors, including the position of the correlate in the antecedent clause and a general preference for similarity between the remnant and its correlate. These factors will now be discussed in the context of how such decisions might be made during sentence processing.

\subsection{Processing clausal ellipsis structures}

There is a large and rapidly expanding literature on ellipsis in sentence processing, most of which will not be reviewed here (see, e.g., Phillips \& Parker 2014; Frazier 2018; or Yoshida 2018). As a starting point, we assume that the sentence processor must engage in at least three tasks when processing clausal elliptical structures (Harris \& Carlson 2018):

\section{Basic tasks in processing ellipsis}

1. Parse the remnant by constructing the appropriate phrase structure for the remnant given the input.

2. Locate the correlate, if any, from the antecedent clause.

3. Construct the elided phrase by regenerating or copying a structure at Logical Form.

The steps in (7) are assumed to follow in the order presented. Assuming that the correlate and remnant match in syntactic category, the category of the remnant must first be parsed (Step 1) before the appropriate correlate can be found (Step 2). We further assume that the correlate must be located prior to constructing the ellipsis (Step 3), as the choice of correlate will determine the meaning of the ellipsis. We concentrate here on two factors that have been implicated in Step 2: Locality and Parallelism. Note that many of the studies reviewed below report reaction time measures. While our study is concerned with offline measures that probe the final interpretation, similar factors are likely to affect online and offline processing. This issue is discussed in more depth in the General Discussion.

\subsubsection{Locality bias}

Sentence processing studies on ambiguous elliptical structures in English have shown that the processer prefers to contrast the remnant with the closest possible DP, typically the object (Frazier and Clifton 1998; Carlson, Dickey, Frazier \& Clifton 2009), a descriptive generalization sometimes called the Locality bias:

Locality bias: Contrast the remnant of the ellipsis with a correlate that is structurally most local in the antecedent clause (Harris 2015; Harris and Carlson 2016).

For example, Carlson (2001) found that remnants in ambiguous negative stripping ellipsis are biased towards the Object (9a) over Subject (9b) contrast interpretations in written questionnaires:

The smuggler followed the gangster, but not the police.

a. ... but the smuggler didn't follow the police.

b. ... but the police didn't follow the gangster.

(Subject contrast) 
The Locality bias appears to hold for other clausal ellipsis structures, such as sluicing. Violating the preference appears to impose a processing cost. Frazier and Clifton (1998) conducted an eye-tracking study on processing sluicing constructions and found out that ambiguous sentences with two potential correlates - subject and object, (10a) were read faster than unambiguous sentences with only one possible subject antecedent (10b). An offline forcedchoice interpretation follow-up showed that the local, object DP was selected as the correlate more often (77\% of responses) than the subject DP for ambiguous sluices (10a).

a. Somebody claimed that the president fired someone, but nobody knows who.

b. Somebody claimed that the president fired Fred, but nobody knows who.

Similar findings have also been observed for focus-sensitive coordination structures (11), analyzed as a special case of stripping ellipsis headed by let alone or much less (Harris 2016; see also Hulsey 2008 and Toosarvandani 2010). Harris \& Carlson (2016) found a local contrast in over $80 \%$ of examples of let alone found in the British National Corpus and the Contemporary Corpus of American English. Their self-paced reading study found immediate online processing costs when a contrastive adjective or prior question indicated a non-local Subject contrast (11b) relative to when it indicated a local Object contrast (11a).

a. The nurse couldn't stand the nicest patient, let alone the meanest one...

(Object contrast)

b. The nicest nurse couldn't stand the patient, let alone the meanest one...

(Subject contrast)

In general, information structure distinguishes between material that is given (known or discussed by discourse participants) from what is new in the discourse. It has been observed that the licensing of ellipsis is sensitive to information status of constituents (Tancredi 1992; Winkler 2018). For material to be elided, it must be given within the discourse. The remnant, or parts therein, must be highlighted prosodically. The remnant and correlate are prosodically marked in clausal ellipsis structures to signal that they relate to or contrast with one another.

One information structural explanation of the Locality bias is that the closest DP is preferred not because it is linearly more accessible, but because it bears pitch accent by default (Frazier \& Clifton 1998; Carlson, Dickey, Frazier \& Clifton 2009; Harris \& Carlson 2018). Assuming that the most deeply embedded constituent tends to bear Nuclear Pitch Accent (Cinque 1993), object DPs are the default bearers of sentence accent in SVO sentences. In silent reading, comprehenders thus default to the object DP as the location for contrastive accent. However, information structural factors, such as explicit and implicit marking of pitch accent or the location of a contrastive adjective (11), may overturn the default, so that a remnant is paired with a non-local correlate.

The results of auditory studies support this account. For example, Carlson, Frazier \& Clifton (2009) found that participants disambiguated ambiguous sluices towards a Subject contrast more often when the subject noun was produced with a contrastive $\mathrm{L}+\mathrm{H}^{*}$ prosodic accent or appeared as the pivot in an it-cleft. Comparable results were observed for focus-sensitive coordination structures in both spoken corpora and controlled experiments (Harris \& Carlson 2018). Similarly, the location of focus-sensitive particles like only also appear to affect the preferred contrast, suggesting that implicit indicators of focus likewise guide comprehension (assuming that such particles assign narrow focus and nuclear stress to their right-adjacent constituent, e.g., Büring \& Hartmann 2001; but see also Harris \& Carlson 2017 for complications). In a written completion study on negative stripping ellipsis, Carlson (2014) found that the location of only strongly influenced whether participants completed fragments like (12) with a Subject or Object contrast remnant.

On Monday (only) the smuggler followed (only) the gangster through the city, but ...

Although stripping ellipsis is often string ambiguous in English, case or other morphosyntactic marking on the remnant can disambiguate the contrast in languages with richer morphology. In German, for example, the case of the determiner (der/den) disambiguates examples like (13), as the remnant and correlate must be marked with the same case. In an auditory electroencephalography study, Stolterfoht \& Bader (2004) found that mismatches in the location of contrastive prosody and case disambiguation led to distinct electrophysiological responses on the remnant, interpreted in terms of a penalty due to increased integration costs 
and prosodic reanalysis. In Stolterfoht et al.'s (2007) silent reading follow up, case mismatches were mediated by the presence of nur ("only") which served to assign the appropriate focus structure in the antecedent clause for the remnant.

\author{
Am Dienstag hat der Direktor den Schüler getadelt, und nicht \\ on Tuesday has the.NOM principal the.ACC student criticized and not \\ der/den Lehrer \\ the.NOM/ACC teacher \\ 'On Tuesday, the principal criticized the students, and not the teacher.'
}

Nonetheless, in the absence of morphological disambiguation, Locality has consistently been shown to be a robust factor in the interpretation of clausal ellipsis in English and other languages (see also Lawn \& Harris 2017 for sluicing in Spanish; Lawn \& Harris 2019 for sluicing in Brazilian Portuguese; and Kaps in press for contrastive ellipsis in Estonian). We now turn to Parallelism, another influential factor in the interpretation of ellipsis.

\title{
1.2.2 Parallelism
}

Early work on conjunction without ellipsis found a processing advantage when the conjuncts were parallel along some dimension (e.g., Frazier et al. 1984; Black et al. 1985; Altmann et al. 1993; Henstra 1996; Frazier et al. 2000). For example, Frazier et al. (1984) observed a reading time advantage when conjoined clauses were syntactically parallel, e.g., both had a DP object, similar thematic roles or matched in prosodic weight (14a), compared to dissimilar structures (14b).
a. Jim believed [ ${ }_{D P}$ all Tom's stories] and Sue believed [ ${ }_{D P}$ Jim's stories].
b. Jim believed $\left[_{D P}\right.$ all Tom's stories $]$ and Sue believed $\left[_{C P}\right.$ Jim's stories were fictious].

Parallelism also influences the ease with which elided content is interpreted (e.g., Greenbaum 1977; Greenbaum \& Meyer 1982; Black et al. 1985; Kaan et al. 2004; Carlson 2002; Dickey \& Bunger 2011). Black et al.'s (1985) study on gapping ellipsis found a comprehension cost when the sentential subjects differed in number (15a) compared to when they were the same (15b), suggesting an account in which the elided verb $\Delta$ is activated with grammatical and semantic features at the ellipsis site (see also Kaan et al. 2004).
a. Your friends mended the car and your brother $\Delta$ the bike.
b. Your friend mended the car and your brother $\Delta$ the bike.

Parallelism may be realized along a number of dimensions: structural (e.g., verbal voice), prosodic (e.g., location and type of pitch accents), and semantic (e.g., animacy, definiteness, etc.), among others. Carlson $(2001,2002)$ proposed that parallelism not only makes coordination structures, with and without ellipsis, easier to process, but also plays a role in how ambiguous sentences are resolved (16).

DP Parallelism Hypothesis: The processor favors analyses in which DPs that share internal properties (have similar syntactic, prosodic, and semantic features) share external properties (appear in similar structural positions within their respective clauses or phrases), and vice versa.

DP Parallelism has been shown to be a key factor in resolving the meaning of ambiguous ellipsis structures, and appears to override Locality in offline interpretation. As discussed above, Harris \& Carlson (2016) found an offline preference to select a subject position noun as a correlate for the remnant in ambiguous focus-sensitive ellipsis structures (11), if each DP contained parallel contrastive adjectives (nicest meanest). However, violating Locality came at an online cost, as subject contrasts elicited longer reading times on the remnant and the region that followed. If subjects simply relied on DP Parallelism to locate the correlate for the remnant, there should not have been a reading time penalty for subject correlates. This pattern thus already suggests a complex interaction between Parallelism and Locality.

While we make reference to multiple aspects of Parallelism below, we will concentrate on DP Parallelism, focusing specifically on the role of parallel morphological and semantic information shared by the remnant and any potential correlates in the antecedent clause. For concreteness, 
we articulate the hypothesis in (17), a direct corollary of (16). Specifically, we will be primarily concerned with how parallel morphology, e.g., case or other nominal morphology, on nonlocal nouns might compete with a preference for a local remnant in resolving ambiguous stripping structures.

Morphological Parallelism: The processor favors correlate-remnant pairings for which the DPs are maximally similar along semantic and morphological dimensions.

The impact of Morphological Parallelism in clausal ellipsis is challenging to investigate in English. Except for pronouns, English does not overtly express case on DPs. As a result, Locality could appear to be favored in English because speakers learn to rely most heavily on general information derived from the structural position of DPs rather than from their morphological shape. As a consequence, Morphological Parallelism between a remnant and its correlate may constitute a less effective strategy for resolving ambiguity in ellipsis structures in English than in languages that constrain how the remnant and correlate can be matched via overt case marking, as in German (13).

We turn to Persian as a testing ground for the relative impact of Locality versus Morphological Parallelism in offline language comprehension. Persian exhibits two features that are important for our purposes. First, it regularly permits word order scrambling (Karimi 2003, 2005), which allows us to manipulate linear order. Second, while Persian is impoverished in its case marking in general, it morphologically marks object DPs that are semantically definite. Persian therefore offers an intriguing middle ground between morphologically poor languages like English and morphologically rich languages like German. In other words, case is rarely specified by overt morphology in English, but is usually specified in German. The selected instances in which Persian does mark case provides an ideal avenue for exploring the relative importance of Locality and Parallelism.

Three hypotheses regarding the interplay between Morphological Parallelism and Locality in resolving ambiguous ellipsis structures in Persian are presented in Section 1.4. First, Persian may pattern like English, showing a strong preference for local correlates, as well as a weaker effect of Morphological Parallelism between nouns. Second, Persian may pattern more like German, relying primarily on parallel DP morphology specifying case. Third, Persian may show a blended strategy for correlate-remnant pairings, e.g., with a bias for morphologically parallel DPs but nonetheless reveal a sensitivity for local correlates, e.g., when the object receives a contrastive interpretation in scrambled sentences.

As discussed, English appears to favor local correlates, though this preference is mitigated by indicators of focal contrast. It is possible that Locality in English arises from the lack of overt morphology on DPs in the language; that is, if DP Parallelism would insufficiently be informative in English, language users might instead rely on structural indicators of contrast. This study was therefore designed to investigate the extent to which the Locality bias results from a last-resort strategy employed when morphological marking on the DPs is insufficient for Morphological Parallelism. We return to these issues in the General Discussion. After a brief overview of the key features of Persian, we present two offline studies to test how ambiguous ellipsis structures are resolved when the two principles are placed in conflict.

\subsection{Resolving Ambiguity in Persian Ellipsis}

\subsubsection{Background on Persian}

The Persian language, also called Farsi, is an Iranian language of the Indo-Iranian sub-branch of the Indo-European family. Persian is a pro-drop language with an unmarked SOV word order. As it is not a subject-prominent language, all phrasal elements may stay inside the $v \mathrm{P}$. Optional movement out of $v \mathrm{P}$ is triggered for topic and focus purposes (Karimi 2005), as demonstrated in (18). ${ }^{6}$ In (18a), the subject and objects are in their base position. However, in (18b), (18c) and (18d), the subject, the direct object, and indirect object have each been topicalized and moved to a sentence-initial position.

6 There are some limitations on the movement of the following elements out of $v \mathrm{P}$ : non-specific subjects and objects, non-verbal elements of complex predicates, and VPs (see Karimi 2005: 18-20 for further information and discussion). 
a. emrooz $\left[_{\mathrm{vP}}\right.$ Kimea ketāb-rā be Parviz mi-d-e $]$

today Kimea book-rā to Parviz DUR-give-3SG

'Kimea will give the book to Parviz today.'

b. Kimea $a_{\mathrm{i}}$ emrooz $\left[_{\mathrm{vp}} \boldsymbol{t}_{\mathrm{i}}\right.$ ketāb-rā be Parviz mi-d-e $]$

Kimea today book-rā to Parviz DUR-give-3sG

c. ketāb-rāa ${ }_{\mathrm{i}}$ emrooz $\left[_{\mathrm{vP}}\right.$ Kimea $\boldsymbol{t}_{\mathrm{i}}$ be Parviz mi-d-e]

book-rā today Kimea to Parviz DUR-give-3SG

d. [be Parviz $]_{\mathrm{i}}$ emrooz $\left[_{\mathrm{vP}}\right.$ Kimea ketāb-rā $\boldsymbol{t}_{\mathrm{i}}$ mi-d-e]

to Parviz today Kimea book-rā DUR-give-3SG (Karimi 2005: 113)

Persian's general schematic clause structure is as shown in (19). Regarding head directionality, Persian is a head-initial language except for VP-level, in which the verb occurs in the final position. ${ }^{7}$

$$
\left[_ { \mathrm { CP } } \left[_ { \mathrm { TopP } } \left[\left[_{\mathrm{FocP}}\left[\left[_{\mathrm{PolP}}\left[\left[_{\mathrm{TP}}\left[{ }_{\mathrm{NegP}}[\mathrm{vP}]\right]\right]\right]\right]\right]\right.\right.\right.\right.
$$

\subsubsection{Specificity/Definiteness}

In Persian, a direct object can be bare ${ }^{8}$ (20a) or it can appear with -rā (20b), pronounced as 'ro' or 'o' in colloquial Persian. In (20a), bare ketāb "book" is understood as non-specific and it does not refer to any particular book but rather a class of items which are books. However, adding the -rā marker requires that the referent be specific. For example, ketāb-rā in (20b) is understood as referring to a particular book known to both the speaker and the hearer (Karimi 2003, 2005; Karimi \& Taleghani 2007).
a. Araz ketāb kharid
Araz book bought.3sG
'Araz bought a book.'
b. Araz ketāb-rā kharid
Araz book-rā bought.3sG
'Araz bought the book.'

Karimi (2003, 2005) has proposed that specific and non-specific objects have different syntactic, morphological, and semantic properties. The non-specific object originates adjacent to the verb in the unmarked word order (21a) while a specific object precedes the indirect object (21b).
a. Parviz barā Kimea ketāb dāstān kharid
Parviz for Kimea book story bought.3SG
'Parviz bought a storybook for Kimea.'
b. Parviz ketāb dāstān-rā barā Kimea kharid
Parviz book story-rā for Kimea bought.3sG
'Parviz bought the story book for Kimea.'

There have been various syntactic and semantic characterizations of the $-r \bar{a}$ marker. ${ }^{9}$ The $-r \bar{a}$ marker has been analyzed as a topic marker (Peterson 1974; Windfuhr 1987), a presupposition

$7 \quad$ It should also be noted that there has been disagreement on the position of sentential negation NegP in Persian. Some researchers (e.g. see Karimi 2005; Taleghani 2006) have proposed that it originates above TP while others (e.g. see Kahnemuyipour 2017) have argued that negation originates $v$ P-internally.

8 In Persian, bare nouns can be indefinite, generic (i), or definite (ii) (e.g. see Jasbi 2020; von Heusinger \& Sadeghpoor 2020 for discussion on Persian nouns).

(i) Ayda ketāb kharid.

Ayda book bought.3sG

'Ayda bought a book/books.'

(ii) ketāb roo miz-e va daftar too kif-et

book on table-be.3SG and notebook in bag-POSS.2SG

'The book is on the table and the notebook is in your bag.' 
marker (Ghomeshi 1997; Ganjavi 2007), a definite marker (Sadeghi 1970; Vazinpour 1977), and a specificity marker (Karimi 2003, 2005). Since specific objects are also definite, in this paper, we will simply assume that $-r \bar{a}$ is a specificity/definiteness marker and leave its other properties aside.

\subsubsection{Topic}

As mentioned in section 1.3.1, in Persian, unlike English, phrasal elements may stay inside the $v \mathrm{P}$; thus, the Spec of TP is not obligatorily filled. Karimi $(2003,2005)$ has proposed that there are two topic positions in Persian (Spec of TP and Spec of TopP), which we briefly discuss in this section.

The Spec of TP is a topic position and can be filled with the subject or object, as shown in (22). In (22a), the subject is topicalized while in (22b) and (22c), the direct object and indirect object are topicalized, respectively.
a. Kimea ${ }_{i}$ emruz $\boldsymbol{t}_{\mathrm{i}}$ ketāb-rā be Parviz mi-d-e
Kimea today book-rā to Parive DUR-give-3SG
'Kimea will give the book to Parviz today.'
b. ketāb-rāa ${ }_{i}$ emruz Kimea $\boldsymbol{t}_{\mathrm{i}}$ be Parviz mi-d-e
book-rā today Kimea to Parviz DUR-give-3SG
c. be Parviz ${ }_{\mathrm{i}}$ emruz Kimea ketāb-rā $\boldsymbol{t}_{\mathrm{i}}$ mi-d-e
to Parviz today Kimea book-rā DUR-give-3SG (Karimi 2005: 113)

Different kinds of topics are thought to be realized in different positions in Persian. According to Karimi (2005), the topicalized element in the Spec of TP is a background topic (also called "continued topic" in Erteschik-Shir et al. 2013) which refers to an element that has already been in the discourse and does not represent a shift of attention in the discourse (e.g., contrasting with another element in the discourse). When the topicalized element is in a contrastive relation with another element in the discourse, it moves to the Spec of TopP. This kind of topic is referred to as shifted topic or contrastive topic. Topics can appear as subjects (23B) or objects $\left(23 \mathrm{~B}^{\prime}\right)$.
A. Kimea ketāb-ā-rā be Parviz dād?
Kimea book-PL-rā to Parviz gave.3SG
'Did Kimea give the books to Parviz?'
B. na, RAHJUE unā-rā be Parviz dād
no Rahjue them-rā to Parviz gave.3sG (Subject contrastive topic)
B'. na, MAJALE-hā-rā Kimea be Parviz dād
no magazine-PL-rā Kimea to Parviz gave.3sG (Object contrastive topic)

In (23B), the subject Rahjue contrasts with the subject Kimea in (23A) while in (23B'), it is the direct object majale that contrasts with the direct object ketāb in (23A). As Rahjue in (23B) and majale in $\left(23 \mathrm{~B}^{\prime}\right)$ function as contrastive topics, they have moved to the Spec of TopP, as illustrated schematically in (24).

a. Subject moves to the Spec of TopP

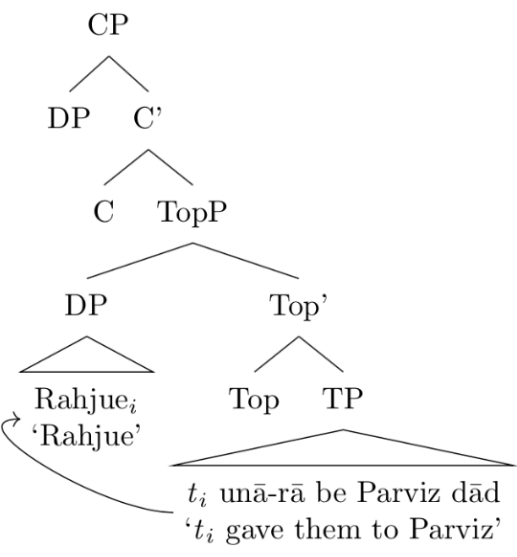


b. Object moves to the Spec of TopP

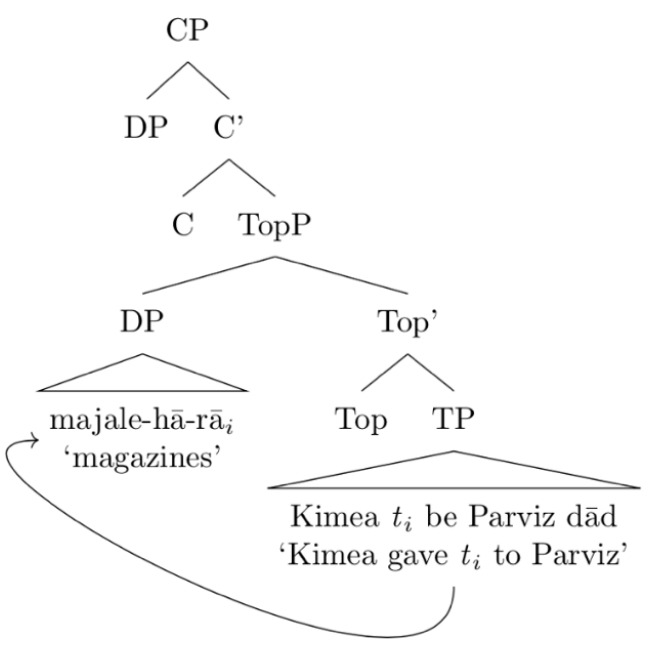

In the following two subsections, we will use the topic structure presented in (24) to account for the structure of scrambled elements and stripping ellipsis.

\subsubsection{Scrambling}

A non-specific object which precedes the verb (e.g. ketāb dāstān "story book" in 21a) can be separated from the verb only if it bears a contrastive stress, as shown in (25) (Karimi 2003, 2005).

$$
\begin{aligned}
& \text { Kimea aqlab ketāb dāstān barā bache-hā mi-khun-e } \\
& \text { Kimea often book story for child-PL DUR-read-3SG } \\
& \text { 'Kimea often reads (a) STORY BOOK for children (rather than a poetry book).' }
\end{aligned}
$$

Unlike non-specific objects, a specific object (marked with -rā) can undergo scrambling and appear in different syntactic positions. It can move to different functional heads such as TopP and FocP in the left periphery. Even though the object in these positions appears in the same position on the surface (i.e. sentence-initial position), it receives contrastive topic or contrastive focus interpretation based on the prosodic stress that is licensed by the particular functional head that hosts the object (26). The movement of the specific object to FocP and TopP is schematically illustrated in (27).

in ketāb dāstān-rā Kimea aqlab barā bache-hā mi-khun-e this book story-rā Kimea often for kid-PL DUR-read-3sG 'It is THIS STORY BOOK that Kimea often reads for the kids.' (Focus interpretation) 'As for this story book, Kimea often reads (it) for the kids.' (Topic interpretation)
a. Object moves to the Spec of FocP

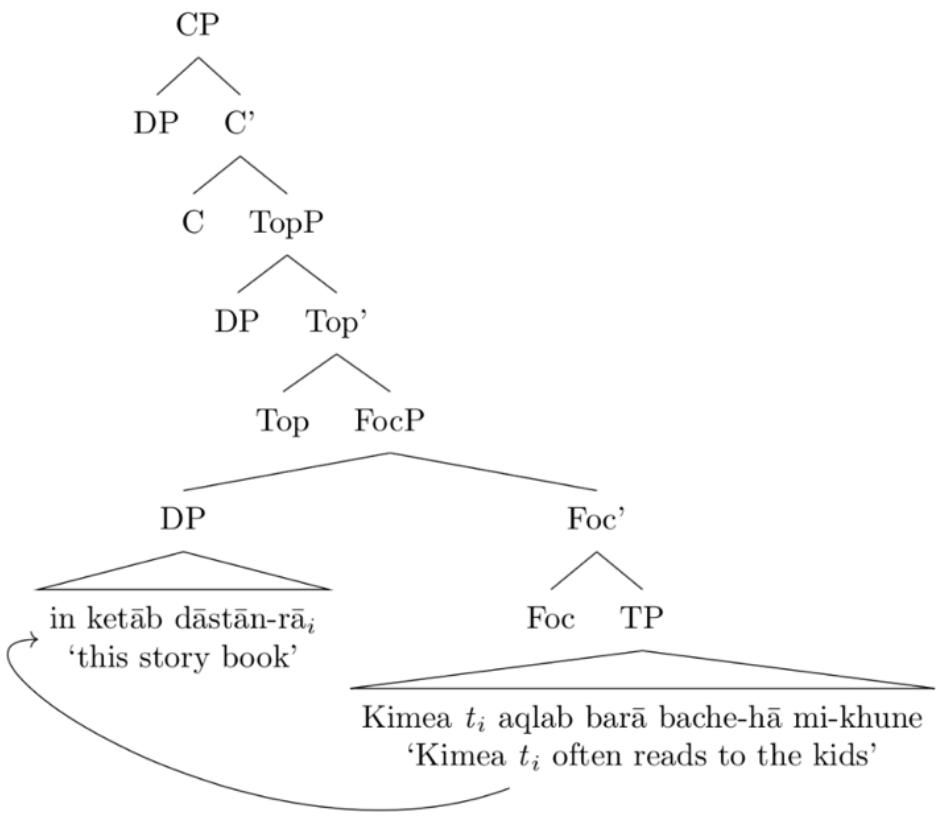


b. Object moves to the Spec of TopP

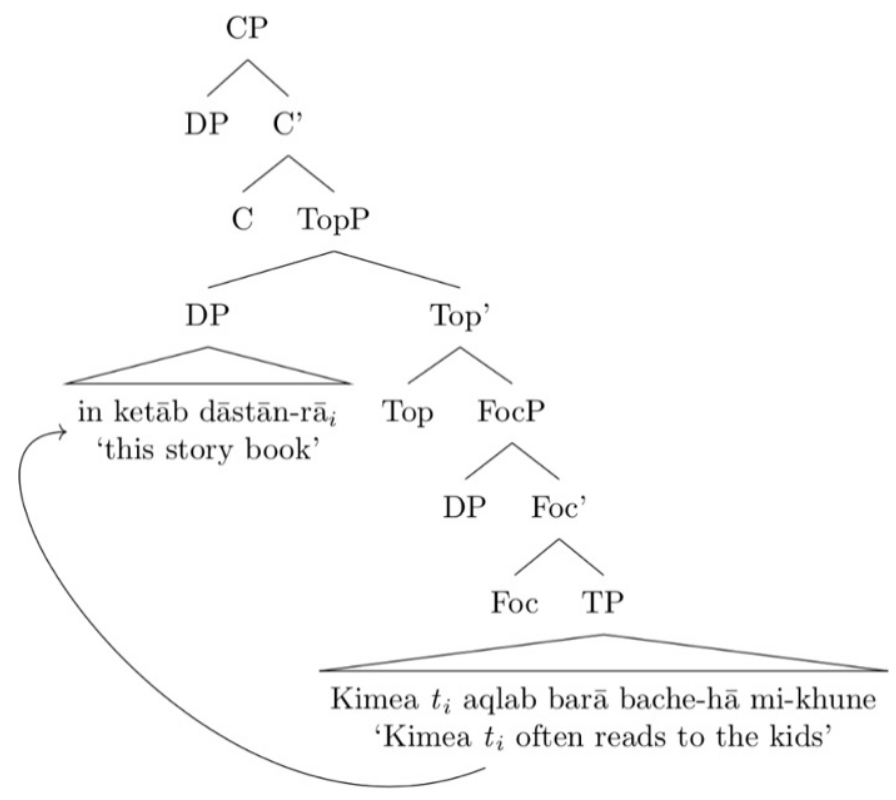

\subsubsection{Stripping Ellipsis}

In stripping ellipsis, as in (2c), the entire clause in the second conjunct is elided except for one element Ben (the remnant) and the negative element not. We find a similar structure in Persian, as in (5), repeated in (28) (Toosarvandani 2015; Rasekhi 2018, 2020).

$$
\begin{array}{lllll}
\text { modir monshi estekhdām=kard } & \text { vali moāven na } \\
\text { manager } & \text { secretary hire=did.3sG } & \text { but } & \text { assistant } & \text { NEG }
\end{array}
$$

i.Object contrast: 'The manager hired a secretary but the manager did not hire an assistant.' ii.Subject contrast: 'The manager hired a secretary but the assistant did not hire a secretary.'

The position of the negative marker in Persian stripping ellipsis (28) differs from English (2c). In Persian, the negative marker na follows the remnant, while in English not precedes the remnant. Rasekhi $(2018,2020)$ argues that such structures in Persian are instances of polarity stripping, also found in other languages including German (4B), French (29), and Spanish (30) (e.g., Morris 2008; Konietzko \& Winkler 2010). ${ }^{10}$ We assume that the negative marker na in polarity stripping originates in the Spec of Pol(arity)P (Rasekhi 2018, 2020), also referred to ¿P (Laka 1990; Depiante 2000; Lopez 1999, 2000; Vicente 2006; among others), a position that can host both negative or affirmative polarity markers. ${ }^{11}$

$$
\begin{aligned}
& \text { Jean aime le chocolat, mais Marie non } \\
& \text { Jean like.3SG the chocolate but Marie no } \\
& \text { 'Jean likes chocolate, but Marie doesn't like chocolate.' }
\end{aligned}
$$

10 Rasekhi $(2018,2020)$ provides evidence that Persian allows negative stripping and pseudo-stripping structures that also involve negation, as shown in (i) and (ii).

\footnotetext{
(i) Araz ketāb kharid, Ayda na (Negative stripping)

Araz book bought.3sg Ayda NEG

'Araz bought book/books, Ayda did not.'

(ii) Araz ketāb kharid, na Ayda (Pseudo-stripping)

Araz book bought.3sg NEG Ayda

'Araz bought book/books, not Ayda.'
}

In Persian negative stripping (i), unlike polarity stripping, there is not an overt coordinator. Rasekhi has proposed that the remnant in polarity stripping and negative stripping functions as contrastive topic and contrastive focus, respectively. She has also argued that pseudo-stripping (ii) doesn't involve ellipsis (See Rasekhi 2018, 2020 for the evidence and discussion).

11 Persian also allows polarity stripping with an affirmative marker. In such structures, as shown in (i), the first clause is negative while the second one is affirmative. The affirmative polarity marker is cherā which literally means "why"; however, it does not have an interrogative interpretation but rather functions as an affirmative polarity marker (Rasekhi 2018, 2019).

(i) modir monshi estekhdām = na-kard vali moāven cherā manager secretary hire $=\quad$ NEG-did but assistant why

a. 'The manager didn't hire a secretary but s/he hired an assistant.' (Object contrast)

b. 'The manager didn't hire a secretary but the assistant hired a secretary.' (Subject contrast) 
Returning to the derivation of polarity stripping in (28), the remnant moāven "assistant" survives ellipsis by moving to the Spec of TopP (31). Following Rasekhi (2018, 2020), we assume that the [E] feature (Merchant 2001) on the Pol head then licenses the deletion of TP at the PF level. ${ }^{12}$

a. Object-contrast remnant topic

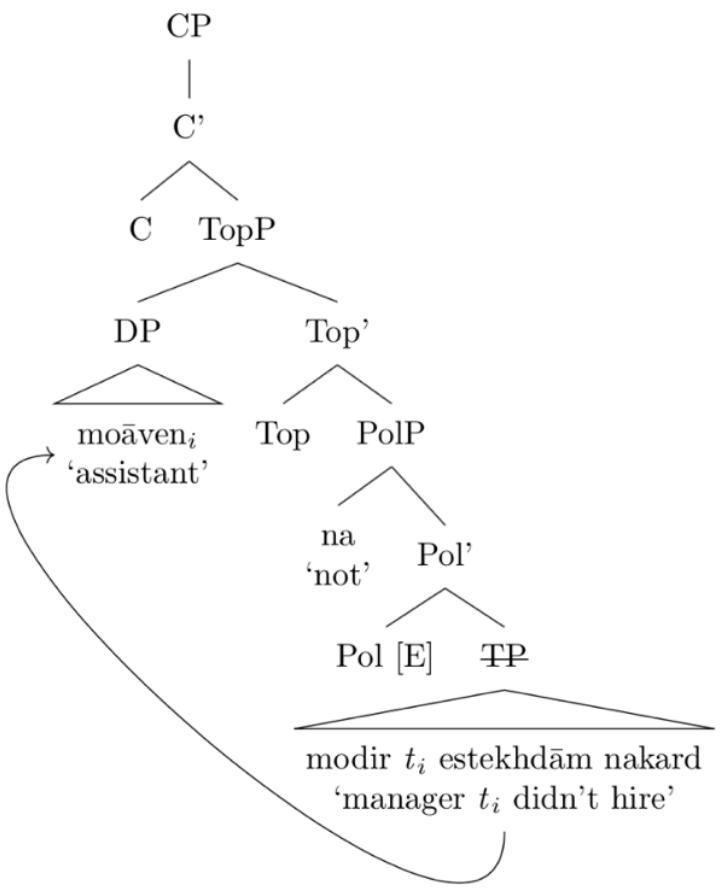

b. Subject-contrast remnant topic

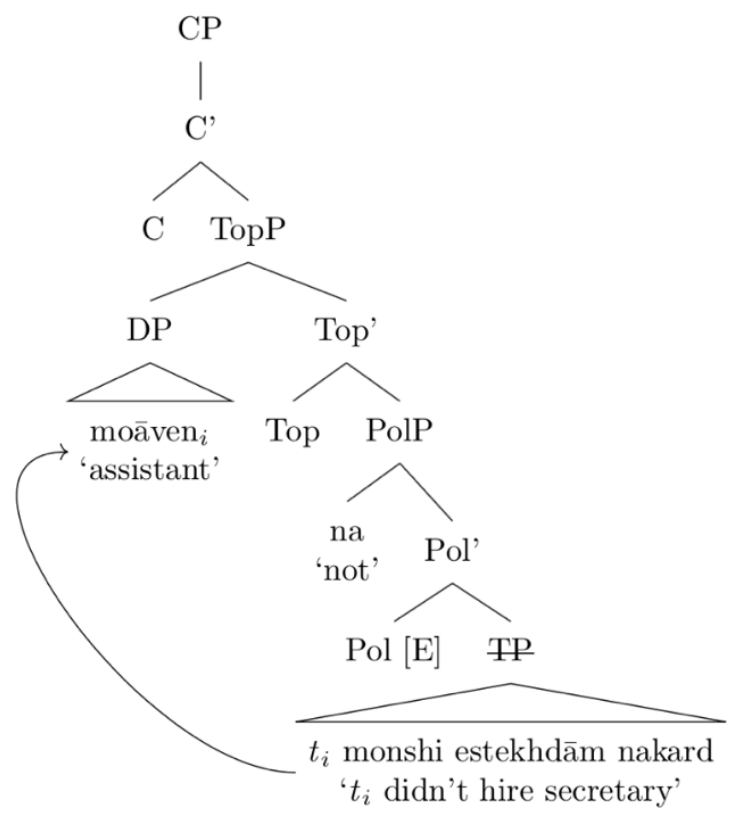

12 The negative marker $n a$ in the Spec of PolP in (31) is not the same as sentential negation. The claim that negation in stripping is not the sentential negation is supported by the fact that we would have two negative markers in these constructions if ellipsis did not take place, as shown in (i).

(i) modir monshi estekhdām =kard vali moāven na monshi estekhdām=na-kard manager secretary hire $=$ did.3SG but assistant NEG secretary hire= NEG-did.3SG Lit: 'The manager hired a secretary but the assistant not, did not hire a secretary.'

Since the remnant "assistant" in this structure has been proposed to be in the Spec of TopP (Rasekhi 2018, 2020), the negative marker na has to be in a position higher than TopP. Therefore, negation has been proposed to originate in the Spec of PolP, which is assumed to host negative and affirmative polarity markers (e.g. (Laka 1990; Depiante 2000; Lopez 1999, 2000). 
If the interpretation of ambiguous stripping structures in Persian is subject to a Locality bias in ambiguous sentences such as (28) above, an Object contrast interpretation should be preferred overall.

As discussed, several accounts for interpreting remnants to clausal ellipsis in English have interpreted Locality with respect to the default placement of Nuclear Pitch Accent (NPA) on the object. It is unclear whether the Locality bias, insofar as it is operational in Persian, is similarly due to default prosody. NPA placement in Persian appears to depend on a host of factors, including verb type, word order and object specificity (e.g., Kahnemuyipour 2009, 2018; Sadat-Tehrani 2007). In SOV sentences, the NPA, shown with underlining in (32), typically appears on the object when it is non-specific (32a), but on the verb when the object bears $-r \bar{a}$ marking (32b). However, the scrambled object O-rā SV order yields NPA on the scrambled object (32c). ${ }^{13}$ Examples (32a-b) come from Sadat-Tehrani (2007).

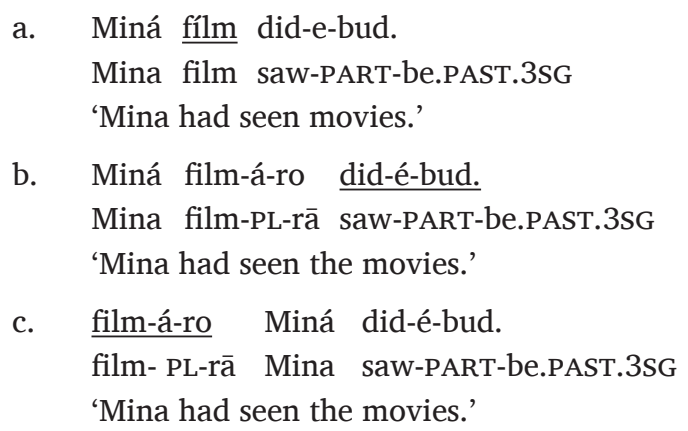

It remains to be seen whether a prosodic account of Locality will suffice in Persian, and the extent to which factors such as word order and specificity influence correlate-remnant pairing preferences.

In addition to Locality, Persian speakers may also be sensitive to Morphological Parallelism in choosing a correlate for the remnant. While the presence of -rā marker (33) should grammatically determine which interpretation is possible, it remains to be seen which interpretation is preferred in unmarked cases.

$$
\begin{array}{llllll}
\text { modir } & \text { monshi-rā } & \text { estekhdām=kard } & \text { vali } & \text { moāven(-rā) } & \text { na } \\
\text { manager } & \text { secretary-rā } & \text { hire=did.3SG } & \text { but } & \text { assistant(-rā) } & \text { NEG }
\end{array}
$$

In the remainder of the paper, we present the results of two offline experimental studies designed to investigate the relative importance of Locality and Parallelism, in the form of -rā marking, in resolving ambiguous polarity stripping structures in Persian. The research questions, hypotheses, and general design of the study are detailed in the following section.

\subsection{Current Study}

The central questions that are addressed in this paper are as follows: Does Persian exhibit a general preference for Locality or Morphological Parallelism in the resolution of ambiguous stripping structures? When these two principles are placed in conflict, which one determines how the structure will be interpreted? In two experimental studies, we study how Locality and Parallelism interact and which, if either, Persian speakers prioritize in offline language comprehension. We explore three options.

First, if Locality is prioritized, we would expect the remnant to contrast with the structurally/linearly most local correlate regardless of Morphological Parallelism between the remnant and correlate. In this case, Object contrasts should be preferred except when they appear in sentence initial position via scrambling. Second, if Morphological Parallelism is prioritized, we would expect a strong preference for the correlate-remnant pair to share a similar morphological/semantic shape regardless of the correlate's location. ${ }^{14}$ It should be

13 The facts surrounding NPA placement in unmarked contexts are considerably more complicated in Persian than portrayed here. For example, NPA is always verb final if the verb is negative, and will appear on certain adverbials before or after the verb. 
noted that the test items in this study were designed so that both Subject and Object contrast interpretations were equally plausible pragmatically.

As a third option, it is possible that one of the Locality or Morphological Parallelism principles is the primary factor in locating a correlate for the remnant, but that the other, non-primary principle could still have a secondary impact in certain contexts - e.g., when the primary factor is insufficient to resolve the pairing. As discussed, English tends to prefer local correlates in clausal ellipsis, but this preference is reduced, but not entirely overturned, when a non-local noun receives pitch accent (Frazier \& Clifton 1998; Carlson, Dickey, Frazier \& Clifton 2009; Harris \& Carlson 2018). In contrast, Persian speakers might in general rely on Morphological Parallelism, given the possibility of $-r \bar{a}$ marking the object, but nonetheless show sensitivity to Locality when the object is scrambled, in which case, the subject is the structurally or linearly more accessible correlate.

To determine which option holds in Persian, we used three kinds of antecedent clauses in our experiments (canonical SOV (34), canonical marked SO-rāV (35), and scrambled O-rāSV (36)) and two types of remnants (unmarked and $-r \bar{a}$ marked). ${ }^{15}$ It should be noted that $-r \bar{a}$ marked nouns are unambiguously objects, and thus remnants with $r \bar{a}$ marking are expected to contrast with objects in the antecedent clause. The -rā marked remnants were included in this study for two reasons. First, they provide a morphologically unambiguous baseline in a full factorial design. Second, previous studies have shown that although pragmatic and prosodic indicators of contrast overturn Locality in English, they nonetheless elicit online processing costs, which might manifest in offline ratings judgments (Harris \& Carlson 2016, 2018). Even in German, where the case of the determiner disambiguates the structure, prosodic mismatches elicited processing difficulty (Stolterfoht \& Bader 2004; Stolterfoht et al. 2007). Thus, there is good evidence that morphological disambiguation does not eliminate the influence of other factors in ellipsis resolution. In the rest of this section, we present our predictions regarding the role of Locality and Morphological Parallelism in interpreting ambiguous ellipsis structures in Persian.

Regarding canonical SOV antecedent clauses (34), if Persian speakers use Locality to match the remnant with its correlate, we expect an Object contrast interpretation to be preferred, in cases where the remnant is either -rā marked or not. However, if Persian speakers depend primarily on Morphological Parallelism for disambiguation, then the Object and Subject contrast interpretation should be roughly matched on balance when the remnant is not -rā marked. In this case, the remnant ("assistant") and the object ("secretary") and subject ("manager") in the antecedent clause have a similar morphological form and meaning. With respect to Morphological Parallelism, an unmarked remnant matches with both subject and object nouns, whereas a -rā marked remnant matches with neither.

$$
\begin{array}{llll}
\text { modir } & \text { monshi estekhdām=kard vali moāven / moāven-rā na } \\
\text { manager } & \text { secretary hire=did.3sG } & \text { but assistant / assistant-rā NEG }
\end{array}
$$

In canonical marked SO-rāV antecedent clauses (35), the object is $-r \bar{a}$ marked. If Locality is the dominant strategy in correlate-remnant pairing, then an Object contrast should again be preferred in this structure, regardless of the form of the remnant. Parallelism, however, predicts that the choice of correlate will entirely depend on whether the remnant is $-r \bar{a}$ marked or not.

$$
\begin{array}{lll}
\text { modir } & \text { monshi-rā } & \text { estekhdām }=\text { kard vali moāven } / \text { moāven-rā na } \\
\text { manager } & \text { secretary-rā hire }=\text { did.3sG } & \text { but assistant } / \text { assistant-rā NEG }
\end{array}
$$

In the third type of antecedent clause (36), the object has been scrambled and surfaces in the sentence-initial position. The -rā marking on the fronted object monshi-rā ("secretary") is required by the grammar; see section 1.3.4. Here, Locality predicts a bias towards a Subject, rather than an Object, contrast. Morphological Parallelism again predicts that the choice of correlate depends on the morphological shape of the remnant.

$$
\begin{array}{lll}
\text { monshi-rā modir estekhdām }=\text { kard vali moāven } / \text { moāven-rā na } \\
\text { secretary-rā }
\end{array}
$$

15 In canonical SOV, the object is in its bare form while in canonical marked SOrāV, the object is -rā marked. In scrambled O-rāSV condition, the object is $-r \bar{a}$ marked and appears in sentence-initial position. Regarding the remnant, it can either be a bare noun (not -rā marked) or it can be -rā marked. Examples for these conditions is provided in Table 2. 
This final case is especially important in determining whether Locality and Morphological Parallelism interact. If, for example, comprehenders largely prefer to match remnants with similar correlates but are still sensitive to the location of the correlate, then scrambling should weaken the bias for Parallelism.

The predictions of Morphological Parallelism and Locality are summarized in Table 1. While -rā marked remnants must unambiguously be interpreted as object remnants, we do not assume that the presence of -rā necessarily obviates the Locality bias, as discussed above. These cells are marked by an asterisk ' $*$ ' in Table 1. Although it is likely that -rā marking will have a strong effect on judgments, it is an empirical question whether other factors continue to influence sentence interpretation, as shown in previous studies on English and German.

\begin{tabular}{llll}
\hline Matrix word order & Remnant Type & Morphological Parallelism & Locality \\
\hline Canonical unmarked & Unmarked & Equal & Object \\
\cline { 2 - 4 } & - rā Marked & NA & Object \\
\hline Canonical & Unmarked & Subject & Object \\
\cline { 2 - 4 } -rā marked & -rā Marked & Object* & Object \\
\hline Scrambled & Unmarked & Subject & Subject \\
\cline { 2 - 4 } -rā marked & -rā Marked & Object* & Subject \\
\hline
\end{tabular}

The cases where Locality and Morphological Parallelism conflict are crucial for determining which principle, if either, is dominant in Persian. There are two such cases. In the first, Canonical -rā marked matrix clauses paired with an unmarked remnant should yield a Subject contrast preference under Morphological Parallelism, but an Object contrast preference under Locality. In the second, Scrambled -rā marked matrix clauses paired with a -rā marked remnant should produce a preference for the scrambled Object under Morphological Parallelism, and a bias towards Subject contrast under Locality. A methodological advantage of the design is that different interpretations are favored under different configurations, so that the patterns cannot be explained as a result of a more general bias towards object or subject correlates.

To summarize, Locality predicts that the structurally or linearly closest noun is the preferred correlate. In contrast, Morphological Parallelism predicts that the noun that shares the most semantic or morphological features is the preferred correlate. If the nouns are equally similar, they should be equally accessible as correlates. However, it is also possible that Persian, like English, does not employ one strategy exclusively in pairing a remnant with a correlate, but may instead be influenced by each factor. In that case, we would expect, say, that a general preference for Morphological Parallelism might be mitigated when a non-parallel noun is found in a more local position, as in the case of Scrambling. We address these possibilities in two experiments reported below: a naturalness rating study and a sentence completion study.

\section{Experiment 1: Naturalness rating study}

We have already seen that ambiguous stripping structures can be interpreted in two ways; the remnant can contrast with the subject or the object in the antecedent clause. The following study tests the predictions of Morphological Parallelism and Locality in a naturalness rating and interpretation task.

\subsection{Participants}

Sixty self-reported native speakers of Persian completed the experiment voluntarily without receiving payment. ${ }^{16}$ Subjects were recruited via email using snowballing sampling techniques to recruit additional participants. To identify inattentive readers, six catch items were included,

1639 participants out of 60 responded to optional demographic questions regarding their location, age, education, and gender. Based on the responses provided, 25 of the participants resided in the US, 1 in Canada, 1 in Europe, and 12 in Iran, and their age range was 21-59. They all had a university degree; 5 of them had a B.A., 16 had an M.A. degree, and 18 of them had a Ph.D. degree. 28 of the participants were female and 11 were male.
Table 1 Predicted correlate preferences according to Morphological Parallelism and Locality. A ‘*' marks cases where the object role of the remnant is grammatically constrained by -rā marking. 
but no participant was removed on this basis. All participants signed an informed consent online before starting the experiment and were told they could leave the experiment at any time they wanted.

\subsection{Materials}

Twenty-four sextets as in Table 2 were constructed in a $2 \times 3$ design, crossing Remnant type (No -rā in remnant and -rā in remnant,) and antecedent clause word order (Canonical SOV, Canonical -rā marked SO-rāV, and Scrambled O-rāSV). In the ellipsis clause, the remnant without $-r \bar{a}$ marking $(\mathrm{a}-\mathrm{c})$ is ambiguous between a Subject and an Object contrast interpretation, as the English translations at the bottom of the table show. However, adding the -ra marking on the remnant grammatically disambiguates the remnant as an object (d-f). As the Subject and Object contrast interpretations illustrate, the sentences in (d-f) do not have a Subject contrast interpretation as the remnant with -rā marking can only be interpreted as an object.

In addition to manipulating the -rā marking on the remnant, we also varied the word order in the antecedent clause. In the Canonical (SOV) word order, there is no -rā marking on the object, while in Canonical -rā marked (SO-rāV) and Scrambled (O-rāSV) word orders, the object is -rā marked. Test items are provided in Appendix A.
Table 2 Experiment 1. Sample experimental sextet in ratings study. Translations show the Object and Subject interpretations, where available.

\begin{tabular}{|c|c|c|}
\hline Antecedent clause & Ambiguous remnant (no - rā in remnant) & Object marked remnant (-rā in remnant) \\
\hline Canonical: SOV & $\begin{array}{l}\text { a. koose māhi gereft, vali panguan na } \\
\text { shark fish caught but penguin NEG }\end{array}$ & $\begin{array}{l}\text { d. koose māhi gereft, vali panguan-rā na } \\
\text { shark fish caught but penguin-rā NEG }\end{array}$ \\
\hline $\begin{array}{l}\text { Canonical -rā } \\
\text { marked: SO-rāV }\end{array}$ & $\begin{array}{l}\text { b. koose māhi-rā gereft, vali panguan na } \\
\text { shark fish-rā caught but penguin NEG }\end{array}$ & $\begin{array}{l}\text { e. koose māhi-rā gereft, vali panguan-rā na } \\
\text { shark fish-rā caught but penguin-rā NEG }\end{array}$ \\
\hline Scrambled: O-rāSV & $\begin{array}{l}\text { c. māhi-rā koose gereft, vali panguan na } \\
\text { fish-rā shark caught but penguin NEG }\end{array}$ & $\begin{array}{l}\text { f. māhi-rā koose gereft, vali panguan-rā na } \\
\text { fish-rā shark caught but penguin-rā NEG }\end{array}$ \\
\hline $\begin{array}{l}\text { Object contrast } \\
\text { interpretation: }\end{array}$ & $\begin{array}{l}\text { 'A/the shark caught fish/the fish but a/the shark did } \\
\text { not catch a/the penguin.' }\end{array}$ & $\begin{array}{l}\text { A/the shark caught fish/the fish but a/the shark did not } \\
\text { catch the penguin. }\end{array}$ \\
\hline $\begin{array}{l}\text { Subject contrast } \\
\text { interpretation: }\end{array}$ & $\begin{array}{l}\text { 'A/the shark caught fish/the fish but a/the penguin did } \\
\text { not catch the fish.' }\end{array}$ & $\mathrm{N} / \mathrm{A}$ \\
\hline
\end{tabular}

The items were carefully constructed to ensure that the remnant could pragmatically contrast equally well with both the subject and object nouns in the matrix clause. Interpreting the ellipsis with a Subject contrast interpretation ("a/the penguin did not catch fish/the fish") and an Object contrast interpretation ("a/the shark did not catch a/the penguin") are equally plausible. $^{17}$

\subsection{Procedure}

The questionnaire was conducted on Ibex Farm (Drummond 2013). Materials were presented in a counterbalanced and randomized order so that the subjects saw only one sentence from each sextet for any experimental item. The 24 experimental sentences were presented with 10 sentences from an unrelated experiment and 20 non-experimental filler sentences, and 6 catch sentences. Each participant saw a total of 60 sentences. Completing the questionnaire took approximately 15 minutes on average.

Participants had two tasks to perform. First, they were instructed to rate naturalness of items like in Table 2 on a Likert scale of 1 (completely unnatural) to 7 (completely natural). Second, they were asked to select an interpretation of the item by choosing one of four options (37), which indicated (a) a Subject contrast, (b) an Object contrast, (c) both, or (d) "I am not sure". Half of the test items had Subject contrast answers followed by the Object contrast answer, while in the other half the order was reversed.

17 The naturalness of test items in this experiment was pre-tested with six native speakers of Persian who did not participate in the main experiment. The participants were asked to determine whether both interpretations were equally possible by rating naturalness of the sentences as in Table 2 on the scale of 1 (completely unnatural) to 7 (completely natural). The purpose of this pre-test was to ensure that the sentences included in the test items can have both Subject and Object contrast interpretations which are equally plausible. Sentences that did not meet this criteria were excluded from the final set of materials. 
Sample interpretation question

mafhoome jomleye "koose māhi gereft vali panguan na" kodām yek meaning sentence shark fish caught.3sG but penguin not which one az gozinehāye zir mibāshad? of options below is

'Which one of the following is the meaning of shark caught fish, but penguin not?'

a. 'Shark caught fish, but penguin did not catch fish.'

b. 'Shark caught fish, but shark did not catch penguin.'

c. Both (a) and (b)

d. I am not sure

We first present results of the naturalness rating task, followed by the interpretation question task. Our predictions for the naturalness ratings portion were as follows. Both Locality and Morphological Parallelism play a role in rating how natural the sentences are; however, if Locality takes priority over Morphological Parallelism, then sentences with a remnant that contrasts with a local correlate should receive higher naturalness ratings. Specifically, Locality predicts an interaction between conditions, in which a -rā marked remnant should receive higher naturalness ratings in the Canonical $-r \bar{a}$ marked condition, as the $-r \bar{a}$ marked object is the most local noun, but lower naturalness ratings in the Scrambled -rā marked condition, as the $-r \bar{a}$ marked object is non-local. However, if Morphological Parallelism is prioritized over Locality, then -rā marking should improve naturalness ratings whenever there is -rā marking on both the remnant and a potential correlate in the antecedent clause (Canonical -rā marked and Scrambled clause types).

Pairing interpretation questions with naturalness ratings allows us to determine how the sentences were interpreted. To review, we predicted that ambiguous remnants, without $-r \bar{a}$ marking (cells a-c in Table 2), can have both Subject and Object contrast interpretations since the remnant can match with both the subject and object in the antecedent clause. However, Morphological Parallelism would predict a preference for Subject contrasts for unmarked remnants (cells b and c), as the object DP in the antecedent clause is -rā marked. However, Locality predicts a general bias towards local correlates (an Object contrast preference in (a-b) and a Subject contrast preference in (c)) regardless of morphology. In contrast, in remnants with -rā marking (conditions $\mathrm{d}-\mathrm{f}$ in Table 2), we expected to observe a strong bias towards the Object contrast interpretation as -rā marking occurs only with object DPs. The Scrambled condition is crucial in that it places the two principles in conflict, and generates a scenario in which we might observe a preference to pair -rā marked remnants in interpretation, but a cost associated with violating Locality in the naturalness ratings.

\subsection{Naturalness ratings results}

The median naturalness rating for each condition is provided in Table 3. Although we only analyze the median values statistically, we also report means and standard errors, shown also in Figure $1 B$, for comparison with studies that have not used ordinal regression models.

\begin{tabular}{llll}
\hline \multirow{2}{*}{ Remnant type } & \multicolumn{3}{c}{ Matrix clause } \\
\cline { 2 - 4 } & Canonical & Canonical Marked & Scrambled \\
\hline Ambiguous & $6(5.14,0.11)$ & $5.5(5.10,0.11)$ & $5(4.75,0.12)$ \\
\hline Object -rā marked & $5(5.14,0.11)$ & $6.5(5.88,0.10)$ & $6(5.56,0.10)$ \\
\hline
\end{tabular}

Values on the Likert scale were treated as inherently categorical, instead of numeric or metric. We analyzed the results as an ordinal linear regression (cumulative link logit) with fixed and random effects using the ordinal package (Christensen 2019) in $R$ ( $R$ Core Team 2020). These models include threshold coefficients, in addition to fixed effects. While we will be interested in fixed effects exclusively, the threshold coefficients serve a similar role as the Intercept in linear models, and are included for replicability. Briefly, a threshold coefficient $x \mid y$ corresponds to the $\log$ odds increase of a value $x$ compared to all the higher ordered categories $y$, provided that all 
other variables in the model are held constant. For example, the coefficient of $4 \mid 5$ corresponds to the log odds of any particular item receiving a rating of 4 or lower, rather than a higher rating of 5,6 , or 7 on a 7 -point scale. Threshold coefficients provide probability thresholds between ordered categories, ignoring any effects of predictor variables. The probabilities of responses from the model are shown in Figure 1A.

\section{A Experiment 1: Probabilities of responses from model}
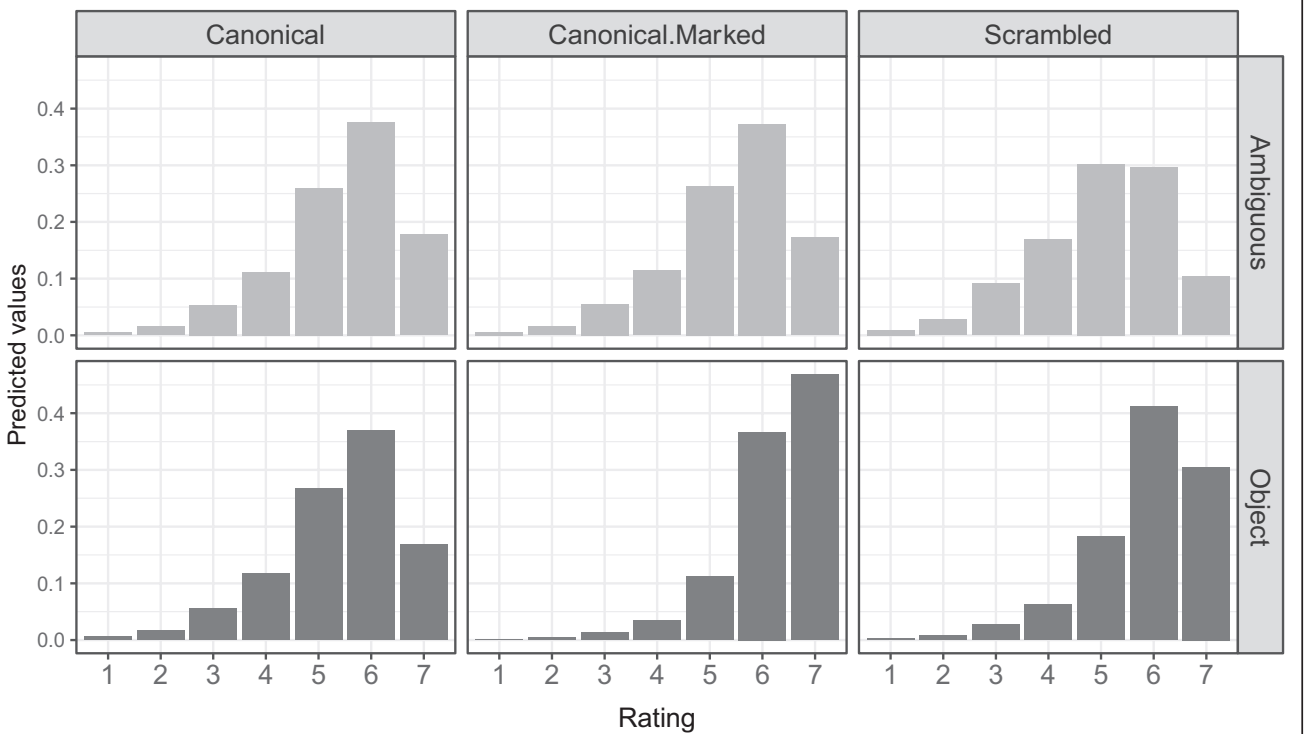

B Experiment 1: Naturalness ratings
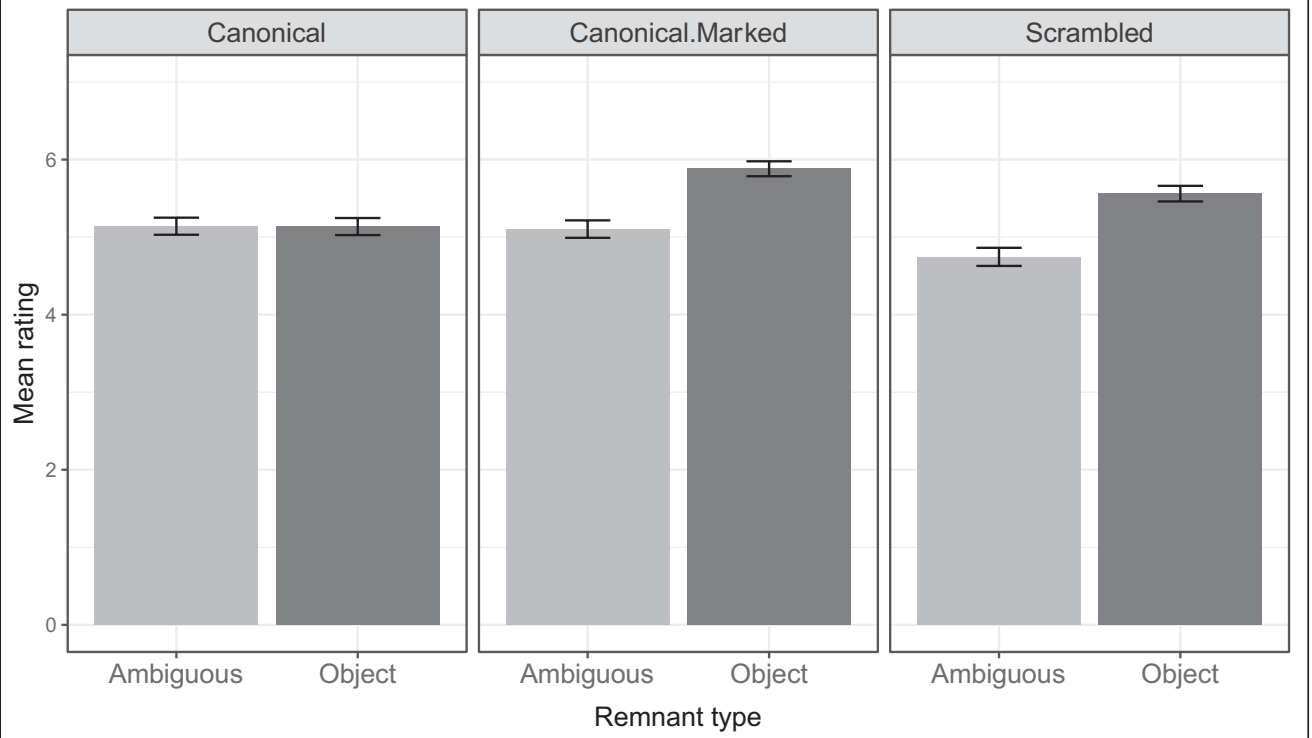

Treatment coding was used to explore the effect of each factor and their interactions against the baseline condition of a Canonical antecedent with an Ambiguous Remnant (Table 2, cell a). The model is presented in Table 4. Compared to the baseline, there was no effect of -rā marking on the remnant (cell a vs. d). There was also no effect of a -rā marked object in the Canonical Marked with an Ambiguous remnant condition (cell a vs. b). However, Scrambling (cell a vs. c) elicited overall lower naturalness ratings in the Ambiguous remnant condition, $z=-3.63$, $p<.001$.

In investigating the interactions between Clause Type and Remnant Type, we compared the effect of a -rā marked remnant in Canonical Marked (the difference between cells b and e) and Scrambled (the difference between cells $c$ and $\mathrm{f}$ ) against the baseline effect in the Canonical antecedent order (the difference between cells a and d). Both interactions were found to be significant; whereas adding -rā marking to the remnant after matrix clauses in sentences with the baseline Canonical order reduced naturalness ratings by 1 point, -rā marking on the remnant increased ratings by 1 point following Canonical Marked (b vs. e), $z=5.84, p<.001$, and Scrambled (c vs. f), $z=5.54, p<.001$, antecedent clauses.
Figure 1 Experiment 1: Probabilities of responses obtained from the first ordinal fixed-effect regression model (Panel A, top). Naturalness ratings means for each condition (Panel B, bottom). 
An analysis of the model's marginal means was conducted to further investigate the interactions using emmeans (Lenth 2021). In Canonical clauses, an Ambiguous remnant was rated no differently than $r \bar{a}$-marked remnants (95\% CI [-0.28, 0.41], $p=0.72$ ). However, Ambiguous rated lower than $r \bar{a}$-marked remnants following both Canonical Marked (95\% CI [-1.81, -1.08$]$, $\hat{\beta}=-1.44, S E=0.19, z=-7.72, p<.001)$ and Scrambled $(95 \%$ CI $[-1.68,0.98], \hat{\beta}=-1.33$, $S E=0.18 \%=-7.48, p<.001)$ antecedent clause orders. ${ }^{18}$

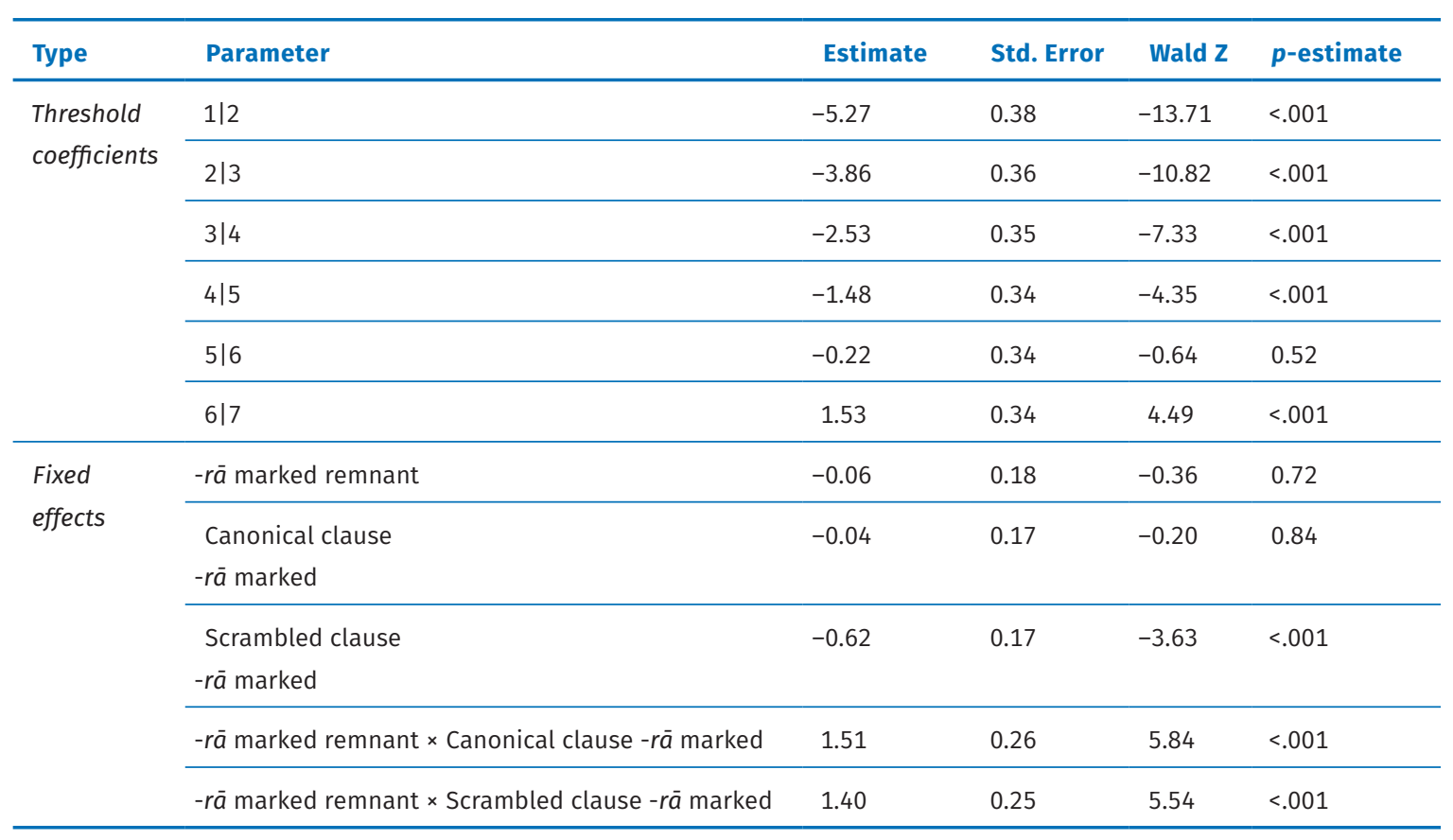

Since both Canonical Marked and Scrambled conditions contained -rā marked DPs in the matrix clause, we constructed a second ordinal regression model to determine whether Scrambled word orders (Table 2, cells $\mathrm{c}$ and $\mathrm{f}$ combined) had an effect over and above $-r \bar{a}$ marking in the Canonical Marked condition (cells b and e combined). ${ }^{19}$ In this model, Canonical Marked and Scrambled conditions were first collapsed to test for a general effect of $-r \bar{a}$ marking. The conditions were then compared against each other, removing the Canonical condition (cells a and d). User-defined contrasts were accordingly specified to compare interactions of theoretical interest, in particular (i) the Combined effect of $-r \bar{a}$ marking in Canonical Marked and Scrambling conditions (contrasts: Canonical $=-0.66$, Canonical Marked $=$ .33 , Scrambled $=.33$ ), and (ii) the effect of Scrambled over Canonical Marked conditions (contrasts: Canonical $=0$, Canonical Marked $=-.5$, Scrambled $=.5$ ).

In this second model, naturalness ratings increased when the remnant was -rā marked, $\hat{\beta}=0.45, S E=0.05, z=8.62, p<.001$. Compared to Canonical Marked antecedents (cells b and e), Scrambling was associated with decreased ratings (cells c and f), $\hat{\beta}=-0.64, S E=0.13$, $z=-4.98, p<.001$. In addition, there was a general naturalness ratings advantage for the combination of Canonical Marked and Scrambled conditions, i.e., items with -rā marking in the antecedent clause, over the Canonical word order, $\hat{\beta}=0.40, S E=0.11, z=3.66, p<.001$.

Interactions indicated that conditions with a -rā marked matrix object patterned together with respect to Remnant Type. While -rā marking on the remnant had no effect on structures with

18 As observed by a reviewer, there was some variation in the complexity and type of nouns in our items. Byitem variation was intentionally included to increase the overall naturalness of our items, as well as to increase the generalizability of our findings to other kinds of NPs. Although differences between NP types are less important for the critical interactions, an additional model was computed that was specified according to the first model, but which excluded items for which the critical NPs varied in complexity in some way (items $2,11,13,15,16,22$, and 24). The results were qualitatively identical, in that there was a ratings penalty for Scrambling in the matrix clause $[\hat{\beta}=-0.68, \mathrm{SE}=0.20, \mathrm{z}=-3.37, \mathrm{p}<.001]$, and interactions showing a greater ratings improvement for $-r \bar{a}$ marking with Canonical Marked $[\hat{\beta}=1.64, S E=0.31, z=5.40, p<.001]$ and Scrambled $[\hat{\beta}=1.38$, $S E=0.30, z=4.62, p<.001]$ orders in the matrix clause.

19 Given that the second model introduces multiple comparisons on the data, the analysis raises the possibility that Type I error is increased. However, all significant effects in the second model remain significant after Bonferroni corrections for multiple comparisons, in which the threshold for significance $(\alpha)$ is scaled according to the additional comparisons $(\alpha=.05 / 2=.025)$.
Table 4 Experiment 1: Ordinal (cumulative link logit) mixedeffects model of naturalness ratings, with treatment coded fixed effects and by-subject and by-items random effects. 
Canonical word order (the difference between cells a and d), it improved naturalness ratings when the object in the matrix clause was also -rā marked (cells b and c compared to e and $\mathrm{f}$ ), $\hat{\beta}=0.73, S E=0.11, z=6.57, p<.001$. However, the size of the effect of $-r \bar{a}$ marking was no different for Canonical Marked antecedents (the difference between cells b and e) compared to Scrambled word orders (the difference between cells $\mathrm{c}$ and $\mathrm{f}$ ), $z=-0.43, p=0.67$, resulting in a 1-point increase for both conditions.

\subsection{Interpretation question results}

The "I am not sure" responses accounted for less than 4\% of responses, and were removed from the data prior to analysis for convenience. The mean percent of interpretation responses for each condition is provided in Table 5, along with $\chi^{2}$-tests on the distribution of Subject, Object, and Both answers in each of the conditions. The distribution of responses is presented in Figure 2.

\begin{tabular}{|c|c|c|c|c|c|}
\hline \multirow{2}{*}{$\begin{array}{l}\text { Matrix word } \\
\text { order }\end{array}$} & \multirow[t]{2}{*}{ Remnant type } & \multicolumn{3}{|c|}{ Correlate } & \multirow[t]{2}{*}{$x^{2}$-test } \\
\hline & & object & Subject & Both & \\
\hline \multirow{2}{*}{$\begin{array}{l}\text { Canonical } \\
\text { unmarked }\end{array}$} & Unmarked & $39 \%(93)$ & $31 \%(73)$ & $30 \%(71)$ & $\chi^{2}(2)=3.75, p=0.15$ \\
\hline & -rā Marked & $86 \%(198)$ & $9 \%(20)$ & $6 \%(13)$ & $\chi^{2}(2)=292.86, p<.001$ \\
\hline \multirow{2}{*}{$\begin{array}{l}\text { Canonical } \\
\text {-rā marked }\end{array}$} & Unmarked & $28 \%(65)$ & $46 \%(107)$ & $27 \%(63)$ & $\chi^{2}(2)=29.45, p<.001$ \\
\hline & -rā Marked & $86 \%(202)$ & $7 \%(16)$ & $7 \%(17)$ & $\chi^{2}(2)=285.53, p<.001$ \\
\hline \multirow{2}{*}{$\begin{array}{l}\text { Scrambled } \\
\text {-rā marked }\end{array}$} & Unmarked & $31 \%(68)$ & $49 \%(108)$ & $20 \%(43)$ & $\chi^{2}(2)=15.76, p<.001$ \\
\hline & -rā Marked & $84 \%(193)$ & $10 \%(24)$ & $6 \%(14)$ & $\chi^{2}(2)=262.78, p<.001$ \\
\hline
\end{tabular}

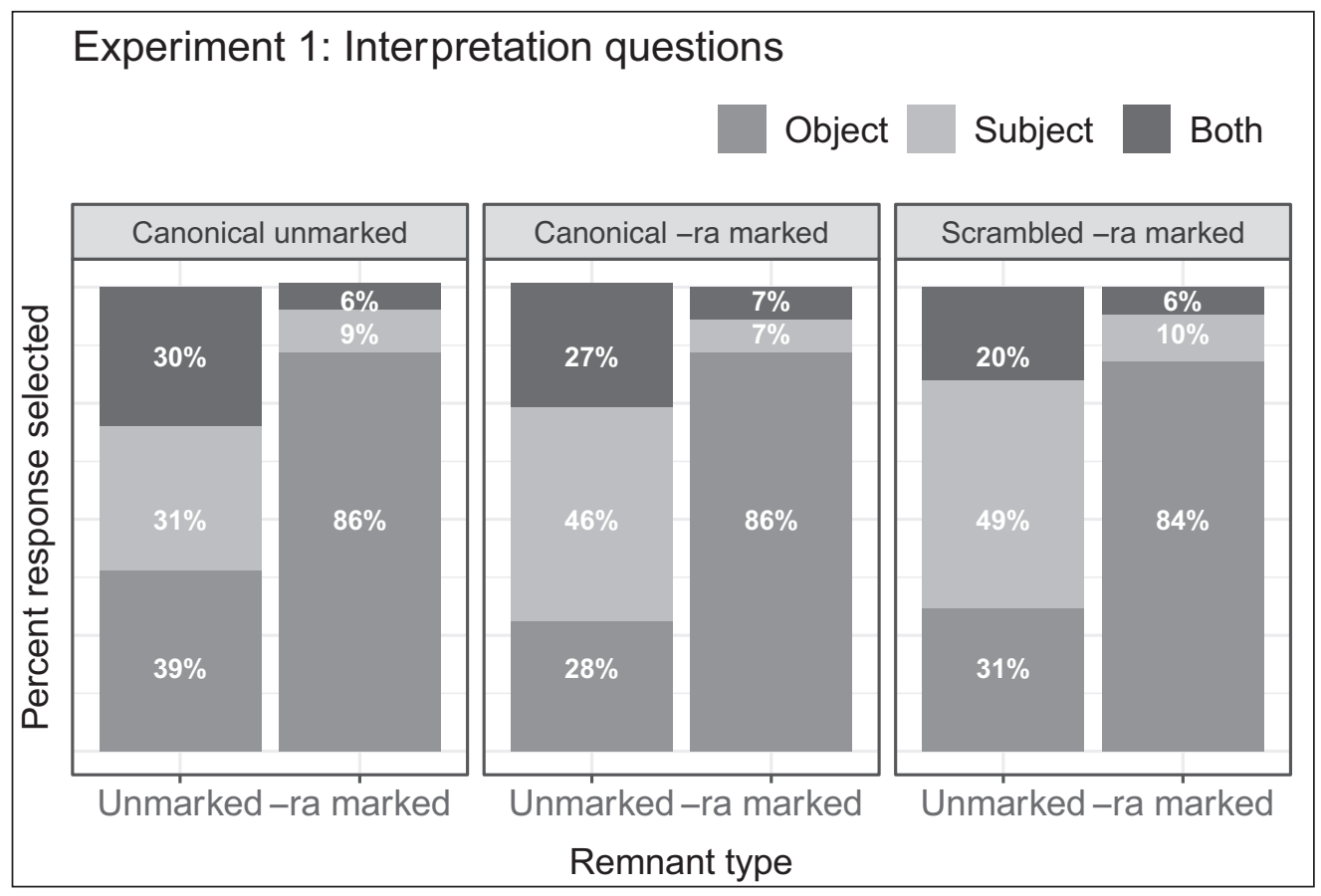

The fact that the dependent variable is an unordered nominal response makes both linear mixed-effects and cumulative link ordinal models inappropriate for analysis. We therefore conducted a series of $\chi^{2}$-tests over the distribution of raw counts for each response within each condition. Sentences were effectively disambiguated by -rā marking on the remnant, garnering approximately $85 \%$ of Object-contrast interpretations overall, regardless of word order and -rā marking in the matrix clause. Morphologically ambiguous remnants, i.e., those that were not -rā marked, generated a more evenly distributed set of responses. Morphologically ambiguous remnants showed a bias towards the Subject contrast interpretation in both Canonical Marked and Scrambled, but not Canonical, orders.
Table 5 Experiment 1: Mean percent of responses for Subject, Object, and Both responses with $\chi^{2}$-tests for each condition. Raw counts are provided in parentheses.

Figure 2 Experiment 1: Percent response selected for Subject, Object, and Both responses in interpretation questions. "I am not sure" responses were excluded. 


\subsection{Discussion}

Results from the naturalness ratings task were compatible with the predictions made by Morphological Parallelism. First, remnants with and without -rā marking were rated as equally acceptable in Canonical clauses. Second, while there was an advantage when -rā marking appeared on both the remnant and the object, the size of the effect was not decreased in Scrambled word orders. The patterns observed in the interpretation question results support the claim that Morphological Parallelism plays a crucial role in remnant-correlate pairing when resolving stripping ellipsis in Persian.

The perception of acceptability and naturalness is influenced by a great number of factors, including complexity, plausibility, frequency, and so on (e.g., Chomsky 1965; Newmeyer 1983; Schütze 2011; Sprouse 2018). For example, interpreting the remnant as a specific object may have been more plausible in the particular experimental sentences provided, making these sentences generally easier to interpret. In addition, our choice of nouns might have implicitly introduced confounding bias into the results. In Table 2, for example, subjects could have relied on extra-grammatical knowledge in interpreting the remnant penguin as contrasting with the matrix object fish rather than the subject shark, even though great care was taken to avoid such bias during stimulus design. Another possibility is that participants may have generally preferred sentences with less ambiguity, resulting in a general ratings advantage for sentences with a $-r \bar{a}$ marked remnant and correlate. Although we think such confounds are unlikely given the plausibility pre-test and the results (especially as the Canonical ambiguous form showed no difference between remnant types), we conducted a follow up study in a method that avoids imposing a specific remnant onto participants, and that allows us to further confirm the patterns in a more open-ended fashion.

\section{Experiment 2: Sentence completion study}

In the second task of Experiment 1, participants chose an interpretation for the remnant from four provided options. In this follow up experiment, participants were given sentences in which the remnant was left blank and were instructed to complete the sentence with an appropriate word (38).

$$
\begin{aligned}
& \text { Ayda dar āvord, vali __ na } \\
& \text { Ayda door brought.3sG but } \\
& \text { Lit: 'Ayda brought door, but }
\end{aligned}
$$

The sentence completion method was chosen to avoid (i) imposing potentially implausible relations into the sentence, as well as (ii) difficult to interpret both and "I am not sure" response options. In addition, the task allowed us to gauge interpretation and production preferences of the participants with a less constrained method.

If participants completed sentence fragments with bare nouns, we would not be able to determine whether they interpreted the remnant as having Subject or Object contrast interpretation. We addressed this issue by controlling the animacy/agency of nouns in the antecedent clause. We assumed that animate completions contrasted with animate subjects, whereas inanimate completions contrasted with inanimate objects. In cases of ambiguity, we also considered whether the completion could plausibly function as an agent in the sentence. This design helped us to determine whether the remnant in the completion contrasted with the Subject (animate/agent) or Object (inanimate/non-agent) correlate.

\subsection{Participants}

Twenty-two self-reported native speakers of Persian participated in the experiment without compensation, and were recruited via the same method as Experiment $1 .{ }^{20}$ Six catch items were included to identify inattentive participants, but no one was removed on this basis.

20 Similar to Experiment 1, participants in this study responded to optional demographic questions regarding their location, age, education, and gender. Based on the responses provided, 16 participants resided in the US, 3 in Canada, and 3 in Iran. Their age range was 20-42. 10 of the participants had Ph.D., 9 had M.A., 2 had B.A. degrees, and 1 had a high school diploma. 5 of the participants were male and 17 were female. 


\subsection{Materials}

Twenty-four sentence fragments with Canonical, Canonical $-r \bar{a}$ marked, and Scrambled antecedents were constructed in which the remnant noun was left blank; see Table 6. Items were designed to be equally compatible with animate/agent (Subject) and inanimate/non-agent (Object) nouns. ${ }^{21}$ This was designed to help us determine whether the participants preferred a Subject or Object contrast interpretation. All items are provided in Appendix B.

\begin{tabular}{|c|c|}
\hline \multicolumn{2}{|l|}{ Antecedent clause } \\
\hline a. Canonical: SOV & $\begin{array}{ll}\text { mard-e javān māshin kharid vali _ na } & \text { na } \\
\text { man-EZ young car bought but } & N E G \\
\text { Lit: 'The young man bought car, but__ not' } & \end{array}$ \\
\hline b. Canonical -rā marked: SO-rāV & $\begin{array}{lll}\text { mard-e javān māshin-rā kharid vali _ na } & \text { na } \\
\text { man-EZ young ca-rā } & \text { NEG } \\
\text { Lit: 'The young man bought the car, but___t. }\end{array}$ \\
\hline c. Scrambled: O-rāSV & $\begin{array}{lll}\text { māshin-rā mard-e javān khaird vali } & \text { na } \\
\text { car-rā } & \text { man-EZ young bought but } & \text { NEG } \\
\text { Lit: 'The car, the young man bought, but } & \text { not.' }\end{array}$ \\
\hline
\end{tabular}

\subsection{Procedure}

The study was administered to participants over the Internet and responses were collected with Ibex Farm. In addition to the 24 experimental sentence fragments, the questionnaire included 43 non-experimental filler fragments and 6 catch fragments. Items were presented in a counterbalanced and individually randomized order so that the subjects responded to only one condition from each triplet. Each participant saw a total of 73 sentences. Completing the questionnaire took less than 20 minutes on average.

Participants were instructed to fill in the blank with the first appropriate word that occurred to them. The animacy/agency of the remnant noun disambiguated the sentence. When participants supplied an animate/agent noun, the remnant was taken to contrast with the subject. However, if they completed the blank with an inanimate/non-agent noun, the remnant was assumed to contrast with the object.

The predictions of the completion study largely follow the previous experiment. A preference for Local correlates would result in a propensity to provide a remnant that contrasted with the closest noun (the object in Canonical sentences and the subject in Scrambled sentences). A preference for Morphological Parallelism would elicit remnant completions that match the correlate, regardless of position.

\subsection{Results}

Completion responses were categorized according to whether the noun provided was animate/agent or inanimate/non-agent and whether it was -rā marked or not. By hypothesis, animate/agent responses indicated a Subject contrast, whereas inanimate/non-agent responses indicated an Object contrast. Results are provided in Table 7.

\begin{tabular}{lllll}
\hline Matrix word order & Contrast & Total & -rā marked & Unmarked \\
\hline Canonical unmarked & Object & $59 \%(56)$ & $0 \%(0)$ & $59 \%(56)$ \\
\cline { 2 - 5 } & Subject & $41 \%(49)$ & $0 \%(0)$ & $41 \%(49)$ \\
\hline Canonical & Object & $56 \%(54)$ & $36 \%(35)$ & $20 \%(19)$ \\
\cline { 2 - 5 } -rā marked & Subject & $44 \%(42)$ & $0 \%(0)$ & $44 \%(42)$ \\
\hline Scrambled & Object & $32 \%(33)$ & $29 \%(29)$ & $3 \%(3)$ \\
\cline { 2 - 5 } -rā marked & Subject & $68 \%(65)$ & $0 \%(0)$ & $68 \%(65)$ \\
\hline
\end{tabular}

21 Similar to Experiment 1, the naturalness of test items in this experiment was pre-tested with six native speakers of Persian who did not participate in the main experiment. The participants were asked to rate naturalness of the sentences as in Table 6 on the scale of 1 (completely unnatural) to 7 (completely natural). The purpose of this pre-test was to ensure that the sentences included in the test items are equally natural with both animate/agent (Subject) and inanimate/non-agent (Object) nouns. Sentences that did not meet this criteria were excluded from the final set of materials.
Table 6 Experiment 2. Sample fragment items in the sentence completion task.
Table 7 Experiment 2: Mean percent responses for each clause type with raw counts in parentheses. Percentages calculated from total within each clause type (Canonical unmarked, Canonical -rā marked, Scrambled -rā marked). 
As subject remnants were never -rā marked, the data were categorically skewed, and a logistic linear mixed-effect regression model of the data could not be fit due to complete lack of variance. Rather than remove the subject remnant level, the relevant comparisons were made with exact one-sided binomial tests on the observed count data. The 95\% confidence interval (CI) is reported along with the significance level of the test for significant comparisons. We first report an analysis that ignores -rā marking on the remnant (shown in the Total column in Table 7), followed by an analysis that distinguishes responses on the basis of -rā marking (shown in the final two columns in Table 7).

Ignoring -rā marking on the remnant, approximately half (49\%) of the remnant completions were inanimate/non-agent, indicating an Object contrast. Object contrasts were numerically preferred in Canonical SOV ( $M=59 \%$ ) and Canonical SOV Marked ( $M=56 \%$ ) conditions, but did not differ significantly from Subject contrasts. However, Scrambled OSV conditions showed significantly fewer Object contrast completions ( $\mathrm{M}=32 \%), 95 \%$ CI $[.23, .43], p<.001$, in favor of Subject contrasts (68\%).

Distinguishing completions by -rā marking on the remnant, there were no cases of -rā marking on animate/agent completions (Subject contrasts) in any condition, which is likely due to the fact that $-r \bar{a}$ marking is reserved for objects. In addition, there were no cases of $-r \bar{a}$ marked (object) remnants following a Canonical matrix clause. In conditions with -rā marked objects in the matrix clause, inanimate/non-agent remnants (Object contrasts) tended to also receive $-r \bar{a}$ marking; Object contrasts were -rā marked more often than not in Canonical Marked (35 of 54 cases) and Scrambled (29 of 32 cases) word orders, 95\% CI [.51, .77], $p<.05$, and 95\% CI $[.75, .98], p<.001$, respectively. ${ }^{22}$

Conversely, contrasts elicited with unmarked remnants also showed a strong effect of Antecedent clause type. While unmarked remnants were essentially evenly distributed between Subject and Object contrasts (56 vs. 49 cases), they were more likely to associate with Subject contrasts in Canonical -rā marked (42 of 61 cases) word orders, 95\% CI [.20 .44], $p<.01$, and Scrambled -rā marked (65 of 68 cases) word orders, 95\% CI [.88 .99], $p<.001$.

\subsection{Discussion}

Remnant completions provided by participants showed a strong sensitivity to clause type and the presence of -rā marked objects in the antecedent. In the Canonical clause condition, responses appeared to be guided by Parallelism, as no remnant was marked with -rā, even though participants rated -rā marked remnants on par with unmarked remnants in Experiment 1. Although there was a numerical bias towards local correlates in Canonical unmarked and Canonical -rā marked clauses, Object and Subject contrasts were provided at statistically equivalent rates (though see footnote 22). Completions supplied in the Canonical -rā marked clause condition indicate that Morphological Parallelism had a non-categorical influence on responses. Participants provided significantly more -rā marked objects in this condition, though bare objects were also provided.

However, the pattern of completions provided for Scrambled antecedents showed a sensitivity to both Locality and Morphological Parallelism. Compared to the baseline condition, participants provided significantly more Subject contrast completions in Scrambled clauses, indicating an increased preference for local correlates in this condition. Participants also provided fewer unmarked Object contrasts, indicating a stronger preference for parallel contrasts.

In addition to corroborating the central findings of the interpretation question portion of Experiment 1, the results provide evidence that Persian speakers are sensitive to Locality in Scrambled conditions. However, having a -rā marked remnant match with the $-r \bar{a}$ marked object in the antecedent clause (in order to maintain Morphological Parallelism) would violate

22 Some of the items may have been lexically or pragmatically biased towards Subject contrasts. At the request of a reviewer, five such items $(6,10,11,17$ and 21$)$ were identified and excluded from a second analysis. In this subset, $54 \%$ of the remnant completions were inanimate/non-agent overall. Significantly more Object contrasts were found for Canonical SOV $(\mathrm{M}=65 \%, 95 \%$ CI $[.54, .74], p<.01)$ and Canonical SOV Marked $(\mathrm{M}=61 \%, 95 \%$ CI $[.52, .72], p<.05)$ conditions. As before, Scrambled OSV conditions showed significantly fewer Object contrast completions $(\mathrm{M}=36 \%, 95 \%$ CI $[.26, .46], p<.01)$. As with the complete data set, Object contrasts were $-r \bar{a}$ marked more often than not in Canonical -rā marked (32 of 47 cases; 95\% CI [.53, .81], $p<.05$ ) and Scrambled (24 of 27 cases; $95 \%$ CI $[.71, .98], p<.001$ ) word orders. No -rā marking was observed in animate/agent completions, indicating a Subject contrast. In all, the data patterned very similarly to the complete data set, and even showed a stronger bias towards -rā marked Object contrasts, in support of the findings obtained for Experiment 1. 
Locality. While these preferences may not be encoded in the grammar, they do appear to strongly affect how comprehenders disambiguate ellipsis structures, interacting in seemingly complex ways.

\section{General Discussion}

In this paper, we presented the results from two experimental studies on disambiguating stripping ellipsis in Persian in which the clause type of the matrix clause (the non-ellipsis antecedent) was manipulated. In Experiment 1, the remnant was either unmarked or -rā marked. Participants rated sentences for naturalness and provided forced-choice responses indicating whether they interpreted the remnant as an Object or Subject contrast. In Experiment 2, the remnant was left blank and participants completed the sentence with a noun of their choosing. The results of the experiments are summarized in Table 8, along with whether Morphological Parallelism or Locality was satisfied in Object or Subject contrasts.
Table 8 Summary of predictions and results for Experiment 1 and 2 .

\begin{tabular}{|c|c|c|c|c|c|c|c|c|}
\hline \multirow{3}{*}{$\begin{array}{l}\text { Manipulation } \\
\text { Matrix word order } \\
\text { Canonical unmarked }\end{array}$} & \multirow{3}{*}{$\begin{array}{l}\text { Remnant Type } \\
\text { Unmarked }\end{array}$} & \multicolumn{3}{|c|}{ Predicted correlate-remnant pairing } & & \multicolumn{2}{|c|}{ Experiment 1} & \multirow{3}{*}{$\begin{array}{l}\text { Experiment } 2 \\
\text { Completion } \\
\text { No bias }\end{array}$} \\
\hline & & \multicolumn{2}{|c|}{ Object contrast } & \multirow{2}{*}{$\begin{array}{l}\text { Subject contrast } \\
\text { Parallel }\end{array}$} & & \multirow{3}{*}{$\begin{array}{l}\text { Ratings } \\
\text { Equal }\end{array}$} & \multirow{2}{*}{$\begin{array}{l}\text { Interpretation } \\
\text { No bias }\end{array}$} & \\
\hline & & Parallel & Local & & - & & & \\
\hline & Marked & - & Local & Parallel & - & & Object bias & Object bias \\
\hline \multirow{2}{*}{$\begin{array}{l}\text { Canonical } \\
\text {-rā marked }\end{array}$} & Unmarked & Parallel & Local & Parallel & - & \multirow[t]{2}{*}{-rā advantage } & Subject bias & Subject bias \\
\hline & Marked & Parallel & Local & - & - & & Object bias & Object bias \\
\hline \multirow{2}{*}{$\begin{array}{l}\text { Scrambled } \\
\text {-rā marked }\end{array}$} & Unmarked & - & - & Parallel & Local & \multirow[t]{2}{*}{-rā advantage } & Subject bias & Subject bias \\
\hline & Marked & Parallel & - & - & Local & & Object bias & Object bias \\
\hline
\end{tabular}

In general, there was clear support that Morphological Parallelism played a role in determining how the polarity ellipsis was interpreted. The first experiment showed that in Canonical (SOV) antecedent clauses both Subject and Object contrasts for morphologically ambiguous remnants (without -rā marking) were rated as equally natural, in keeping with the predictions of Morphological Parallelism. Additional support for Morphological Parallelism came from Canonical-marked and Scrambled cases in which the main clause object was $-r \bar{a}$ marked. In these conditions, sentences with a -rā marked remnant were rated higher than remnants without -rā marking. As -rā marked remnants are grammatically constrained to be objects, participants appeared to prefer sentences in which the contrastive relationship was morphologically explicit.

Responses to interpretation questions provided additional support for the importance of Morphological Parallelism in resolving ellipsis in Persian. As ambiguous remnants were not -rā marked, unmarked Subject and Object DPs would be expected to be equally accessible as correlates under Morphological Parallelism, as was the case. However, when the Object DP was -rā marked, Subject contrasts were selected more often, indicating that participants preferred to match an unmarked remnant with the unmarked Subject DP. As expected, there was a strong preference for Object DPs across conditions when the remnant was -rā marked. In this experiment, there was no indication in either naturalness ratings or interpretation questions that disambiguating polarity stripping ellipsis in Persian showed any sensitivity to Locality.

In the second experiment, participants completed sentence fragments with a remnant. The results again supported the predictions of Morphological Parallelism in Canonical and Canonical Marked conditions. However, more Subject contrast remnants were provided in the Scrambled condition than in other conditions. Again, these preferences were strongly modulated by the presence of $-r \bar{a}$ marking on the remnant. We interpreted this pattern as evidence for a limited effect of Locality; a Subject contrast became more tempting once it was the most local option. Nonetheless, a Subject contrast in this configuration did not violate Morphological Parallelism.

The contrast between the two experimental paradigms further highlights the importance of task in assessing native speaker intuitions. Although participants appeared to accept Object contrast remnants after Scrambled clauses, the completions indicate that Subject contrast remnants were preferred in this configuration. Pairing the two paradigms allowed us to detect the subtle effect of Scrambling on remnant contrast preference. 
In general, the role of Morphological Parallelism in disambiguating ellipsis structures in Persian is highly compatible with previous studies in the literature showing that Parallelism influences the interpretation and processing of various ellipsis structures in English, including stripping/bare argument ellipsis (Paterson et al. 2007; Carlson 2013), sluicing (Frazier \& Clifton 1998; Carlson, Dickey, Frazier \& Clifton 2009), gapping (Carlson 2001, 2002), and focus-sensitive coordination (Harris \& Carlson 2016, 2018). However, our results show a more constrained role for Locality in Persian, in that the preference for Local correlates manifests primarily in Scrambled sentences, in structures that do not contravene Parallelism. Overall, our results suggest that the processer is sensitive to a complex interaction of factors when interpreting ellipsis structures. In particular, the processor considers word level information, as well as syntactic or information structural status, when attempting to establish remnantcorrelate pair in interpreting ellipsis (as in Step 2 in (7)).

More broadly, this study aims to expand the range of languages in experimental research on ellipsis. While theoretical approaches to ellipsis sample widely from the world's languages (e.g., the studies collected in van Craenenbroeck \& Temmerman 2018), the psycholinguistic literature on ellipsis is arguably farther behind in this respect (but see, for example, the experimental studies on French, English, Spanish, and Saudi Arabic collected in Abeillé et al. 2018). It is increasingly important that experimentation expand its scope to languages beyond English, so that we may discern which processing principles and tendencies are general, or even universal, and which strategies reflect the features of a particular language (see comments in Norcliffe et al. 2015). Increasing the linguistic diversity in language processing research will provide a better and broader understanding of the architecture of the language processing system and the extent to which its structure reflects the properties of the language. In our case, we believe that Persian provides an informative middle ground between morphologically impoverished languages like English and relatively morphologically rich languages like German, in determining how principles like Parallelism and Locality might be realized differently across languages.

We speculate that these particular principles are, in fact, distinct realizations of the same underlying prerequisite for establishing contrast between the remnant and the correlate. A contrastive relation between two elements in clausal ellipsis intuitively requires that they be comparable along the appropriate semantic dimension (e.g., Barros \& Vincente's 2016 Remnant Condition for sluices). If so, a preference for Morphological Parallelism might then reflect a heuristic strategy for constraining members of an alternative set on the basis of the morphosyntactic form of elements involved (the remnant with possible correlates). Languages with rich overt morphology would be predicted to show a more general dependence on Morphological Parallelism, as the constituents in contrast would be constrained more directly by surface form.

In contrast to Morphological Parallelism, Locality might reflect an imperfect proxy for prosodic aspects of information structure (Büring 2012, 2016; Truckenbrodt 1995; Harris \& Carlson 2018). Although the descriptive generalization for Locality has been phrased in terms of linear or structural location, the principle behind it may relate more deeply to the assignment of default prosody and, ultimately, information structure. In particular, languages with poor overt morphology might rely more heavily on general or default locations for information structure, such as topic or focus, when interpreting clausal ellipsis structures.

One way to reconcile the patterns observed in our studies is that the morphosyntax of Persian constrains which constituents the processor takes as contrastive, resulting in a strong, general preference for Morphological Parallelism in finding a correlate for a remnant of ellipsis. Assuming that topics are not strongly associated with a particular position in Persian, Locality may only weakly influence how the correlate for polarity stripping is determined. Locality might nonetheless occupy a secondary role in interpretation, which only manifests in limited cases when Parallelism would not be violated. Additional testing is required to test the validity of this account.

These speculations naturally raise several questions and predictions to be explored in future research. For example, information structure is likely to play an important role in finding a correlate for contrastive ellipsis structures, as in the type of ellipsis explored here. Assuming that the remnant and correlate in Polarity stripping are contrastive topics, the choice of correlate may be related to independent factors determining the topicality of each noun in the 
antecedent clause. As our sentences appeared without explicit context, lexical considerations may also have played a non-trivial role in interpretation, e.g., whether a particular noun was likely to serve as a topic and whether it provided a suitable contrast for the remnant.

We also predict that information structure factors influence the interpretation of different kinds of ellipsis structures in different ways. We have concentrated here on Polarity stripping, in which the remnant is understood as a contrastive topic. However, in nearly identical cases of Negative stripping ellipsis, the remnant has been argued to be in a contrastive focus position (e.g., see Morris 2008 for French and Spanish; Konietzko \& Winkler 2010 for German; Rasekhi 2018, 2020 for Persian).

In a related study on German, Konietzko \& Winkler (2010) compared Polarity stripping (39a) and Negative stripping (39b) ellipsis with an animate/agent remnant (Anna) that highly encouraged a Subject contrast interpretation. In their written questionnaire study, Negative stripping examples were judged to be less acceptable than Polarity stripping counterparts. In spoken versions, however, Negative stripping sentences were rated just as grammatical as Polarity stripping sentences once the remnant was rendered with contrastive prosody.

\section{a. Polarity stripping ellipsis}

Sandy spielt Fußball, aber Anna nicht

Sandy played football but Anna NEG

'Sandy played football, but not Anna.'

b. Negative stripping ellipsis

Sandy spielt Fußball, aber nicht Anna

Sandy played football but NEG Anna

'Sandy played football, but not Anna.'

Their finding suggests that contrastive prosody is crucial for the perception of well-formedness in these structures and that a default (non-contrastive) prosody may have been assigned to the remnant during silent reading. Similar prosodic considerations may have influenced how participants interpreted and rated the materials in our study.

In this paper, we have reported effects that manifest relatively late in the sentence comprehension process. Further studies could examine the early components of processing, e.g., by recording the speed at which subjects accept or reject ellipsis structures that conform to Morphological Parallelism and/or Locality. We think it's possible that Locality might have a stronger influence on online processing than was observed here. As in Harris and Carlson (2016), non-local correlates that provide a better contrast with the remnant might nonetheless incur a processing cost. Additional study is required to assess this possibility.

In summary, the results of two experimental studies on ambiguous Polarity stripping found that Persian speakers largely tended to disambiguate ellipsis structures by Morphological Parallelism more than Locality. We speculated that Morphological Parallelism and Locality represent two distinct, yet related, strategies for locating an appropriate contrasting correlate for the remnant, and sketched an account in which languages might rely more heavily on one strategy over another given the morphosyntactic properties of the language. We expect that further research into this area will reveal even more interesting complications regarding the information structure and prosodic interpretation of the constituents in these structures.

\section{Abbreviations}

$\mathrm{NEG}=$ negation, $\mathrm{EZ}=$ Ezafe, $\mathrm{SG}=$ singular, $\mathrm{PL}=$ plural, $\mathrm{NOM}=$ nominative, $\mathrm{ACC}=$ accusative, DUR $=$ durative, POSS $=$ possessive, $\mathrm{PAST}=$ past, $\mathrm{PART}=$ participle

\section{Additional Files}

The additional files for this article can be found as follows:

- Appendix A: Experiment 1 Test Items. DOI: https://doi.org/10.16995/glossa.5881.s1

- Appendix B: Experiment 2 Test Items. DOI: https://doi.org/10.16995/glossa.5881.s2 


\section{Acknowledgements}

The authors would like to thank Maziar Toosarvandani, Katy Carlson, Elsi Kaiser, Marju Kaps, participants at UCLA's Psycholinguistics seminar, and audiences at the 3rd California Meeting on Psycholinguistics, Experimental and Corpus-based Approaches to Ellipsis 2019, and the 33rd CUNY Human Sentence Processing Conference for their comments, questions, and feedback. The authors would also like to thank UCLA undergraduate research assistants, Benita Sadeh and Ashley Ghodsian, for their help constructing the materials.

\section{Funding information}

This research has been supported by Roshan Cultural and Heritage Institute postdoctoral fellowship awarded to the first author.

\section{Competing interests}

The authors have no competing interest to declare.

\section{Author affiliations}

Vahideh Rasekhi (D) orcid.org/0000-0001-5055-1845

University of California, Los Angeles, 3125 Campbell Hall, Los Angeles, CA 90095

Jesse A. Harris (D) orcid.org/0000-0001-7222-8344

University of California, Los Angeles, 3125 Campbell Hall, Los Angeles, CA 90095

\section{References}

Abeillé, Ann, Philip Miller \& Jeffery T. Runner (eds.). 2018. Special collection Experimental Approaches to Ellipsis, Glossa.

Aelbrecht, Lobke. 2010. The Syntactic Licensing of Ellipsis. John Benjamins Publishing Company. DOI: https://doi.org/10.1075/la.149

Altmann, Gerry T. M., Judith-Ann Henstra \& Alan Garnham. 1993. Processing coordinated structures. Poster presented at the 6th Annual CUNY Conference on Human Sentence Processing. Amherst, Massachusetts.

Barros, Matthew \& Luis Vicente. 2016. A remnant condition for ellipsis. In Kyeong-min Kim, Pocholo Umbal, Trevor Block, Queenie Chan, Tanie Cheng, Kelli Finney, Mara Katz, Sophie Nickel-Thompson, \& Lisa Shorten (eds.), Proceedings of the 33rd West Coast Conference on Formal Linguistics, 57-66. Somerville, MA: Cascadilla Proceedings Project.

Black, Maria, Max Coltheart \& Sally Byng. 1985. Forms of coding in sentence comprehension during reading. In Max Coltheart (ed.), Attention and performance XII: The psychology of reading, 655-672. Hillsdale, NJ: Lawrence Erlbaum Associates.

Büring, Daniel. 2012. Focus and Intonation. In G. Russell, \& D. G. Fara (eds.), Routledge companion to the philosophy of language, 103-115. London, UK: Routledge.

Büring, Daniel. 2016. Intonation and meaning. Oxford, UK: Oxford University Press. DOI: https://doi. org/10.1093/acprof:oso/9780199226269.001.0001

Büring, Daniel \& Katharina Hartmann. 2001. The Syntax and Semantics of Focus-Sensitive Particles in German. Natural Language \& Linguistic Theory 19(2). 229-281.

Carlson, Katy. 2001. The effects of parallelism and prosody on the processing of gapping structures. Language and Speech 44. 1-26. DOI: https://doi.org/10.1177/00238309010440010101

Carlson, Katy. 2002. Parallelism and prosody in the processing of ellipsis sentence. Outstanding Dissertations in Linguistics series. New York: Routledge.

Carlson, Katy. 2013. The role of only in contrast in and out of context. Discourse Processes 50(4). 249-275. DOI: https://doi.org/10.1080/0163853X.2013.778167

Carlson, Katy. 2014. Predicting contrast in sentences with and without focus marking. Lingua 150. 78-91.

Carlson, Katy, Lyn Frazier, Charles Clifton, Jr. 2009. How prosody constrains comprehension: A limited effect of prosodic packaging. Lingua 119. 1066-1082. DOI: https://doi.org/10.1016/j. lingua.2008.11.003

Carlson, Katy, Michael Walsh Dickey, Lyn Frazier \& Charles Clifton, Jr. 2009. Information structure expectations in sentence comprehension. The Quarterly Journal of Experimental Psychology 62(1). 114-139. DOI: https://doi.org/10.1080/1747021070188017

Chomsky, Noam. 1965. Aspects of the theory of syntax. Cambridge: MIT Press. DOI: https://doi. org/10.1017/S0022226700012998 
Christensen, Rune, H. B. 2019. Regression models for ordinal data. R package version 2019.12-10. https:// CRAN.R-project.org/package $=$ ordinal.

Chung, Sandra. 2013. Syntactic identity in sluicing: How much, and why. Linguistic Inquiry 44(1). 1-39. DOI: https://doi.org/10.1162/LING_a_00118

Chung, Sandra, William Ladusaw \& James McCloskey. 1995. Sluicing and Logical Form. Natural Language Semantics 3. 239-282. DOI: https://doi.org/10.1007/BF01248819

Cinque, Guglielmo. 1993. A null theory of phrase compound stress. Linguistic Inquiry 24(2). $239-297$.

Culicover, Peter W. \& Ray Jackendoff. 2005. Simpler syntax. Oxford: Oxford University Press.

Depiante, Marcela. 2000. The syntax of deep and surface anaphora: A study of null complement anaphora and stripping/bare argument ellipsis. Connecticut: University of Connecticut dissertation. DOI: https:// opencommons.uconn.edu/dissertations/AAI9988039

Dickey, Michael W. \& Ann C. Bunger. 2011. Comprehension of elided structure: Evidence from sluicing. Language, Cognition and Neuroscience 26(1). 63-78. DOI: https://doi. org/10.1080/01690961003691074

Drummond, Alex. 2013. Ibex Farm. http://spellout.net/ibexfarm.

Erteschik-Shir, Nomi, Lena Ibnbari \& Sharon Taube. 2013. Object ellipsis as topic drop. Lingua 136. 145-169. DOI: https://doi.org/10.1016/j.lingua.2013.07.009

Faghiri, Pegah \& Pollet Samvelian. 2016. How much structure is needed: The case of the Persian VP. In Dough Arnold, Miriam Butt, Berthold Crysmann, Tracy Holloway King \& Stefan Müller (eds.), Proceedings of the Joint 2016 Conference on Head-driven Phrase Structure Grammar and Lexical Functional Grammar, 236-254. Polish Academy of Sciences, Warsaw, Poland. Stanford, CA: CSLI Publications.

Fiengo, Robert \& Robert May. 1994. Indices and Identity. Cambridge, MA: MIT Press.

Fox, Danny. 2000. Economy and semantic interpretation. Cambridge, Massachusetts: MIT Press.

Frazier, Lyn. 2018. Ellipsis and psycholinguistics. In Jereon van Craenenbroeck \& Tanja Temmerman (eds.), The Oxford Handbook of Ellipsis, 253-275. Oxford: Oxford University Press.

Frazier, Lyn, Alan Munn \& Charles Clifton, Jr. 2000. Processing coordinate structures. Journal of Psycholinguistic Research 29(4). 343-370. DOI: https://doi.org/10.1023/A:1005156427600

Frazier, Lyn \& Charles Clifton, Jr. 1998. Comprehension of sluiced sentences. Language and Cognitive Processes 13(4). 499-520.

Frazier, Lyn, Lori Taft, Tom Roeper, Charles Clifton, Jr. \& Kate Ehrlich. 1984. Parallel structure: A source of facilitation in sentence comprehension. Memory \& Cognition 12(5). 421-430. DOI: https://doi. org/10.3758/BF03198303

Ganjavi, Shadi. 2007. Direct objects in Persian. Los Angeles, CA: University of Southern California dissertation.

Ghomeshi, Jila. 1997. Topics in Persian VPs. Lingua 102. 133-167. DOI: https://doi.org/10.1016/S00243841(97)00005-3

Greenbaum, Sidney. 1977. Judgments of Syntactic Acceptability and Frequency. Studia Linguistica 31(2). 83-105. DOI: https://doi.org/10.1111/j.1467-9582.1977.tb00649.x

Greenbaum, Sidney \& Charles F. Meyer. 1982. Ellipsis and coordination: Norms and preferences. Language \& Communication, 2(2). 137-149. DOI: https://doi.org/10.1016/0271-5309(82)90004-0

Hankamer, Jorge \& Ivan Sag. 1976. Deep and Surface Anaphora. Linguistic Inquiry 7(3). 391-428.

Hardt, Daniel. 1993. Dynamic interpretation of verb phrase ellipsis. Linguistics and Philosophy 2. 185-219.

Harris, Jesse A. 2015. Structure Modulates Similarity-Based Interference in Sluicing: An Eye Tracking study. Frontiers in Psychology 6. DOI: https://doi.org/10.3389/fpsyg.2015.01839

Harris, Jesse A. 2016. Processing let alone coordination in silent reading. Lingua 169. 70-94. DOI: https:// doi.org/10.1016/j.lingua.2015.10.008

Harris, Jesse A. \& Katy Carlson. 2016. Keep it local (and final): Remnant preferences in "let alone" ellipsis. The Quarterly Journal of Experimental Psychology 69(7). 1278-1301. DOI: https://doi.org/10.1 080/17470218.2015.1062526

Harris, Jesse A. \& Katy Carlson. 2017. Association with focus for focus-sensitive particles: Differences between "only" and "even" in silent reading. Talk presented at The 91st Annual Meeting of the Linguistic Society of America, Austin, TX.

Harris, Jesse A. \& Katy Carlson. 2018. Information Structure Preferences in Focus-Sensitive Ellipsis: How Defaults Persist. Language and Speech 61(3). 480-512. DOI: https://doi. org/10.1177/0023830917737110

Henstra, Judith-Ann. 1996. On the parsing of syntactically ambiguous sentences: Coordination and relative clause attachment. Falmer: University of Sussex dissertation.

Hulsey, Sarah M. 2008. Focus sensitive coordination. Cambridge, MA: MIT Massachusetts Institute of Technology dissertation.

Jasbi, Masoud. 2020. The suffix that makes Persian nouns unique. In Richard Larson, Sedigheh Moradi \& Vida Samiian (eds.), Advances in Iranian Linguistics, 107-118. John Benjamins Publishing Company. DOI: https://doi.org/10.1075/cilt.351.06jas 
Jayaseelan, Karattuparambil A. 2001. IP-internal topic and focus phrases. Studia Linguistica 55(1). 39-75. DOI: https://doi.org/10.1111/1467-9582.00074

Kaan, Edith, Frank Wijnen \& Tamara Y. Swaab. 2004. Gapping: Electrophysiological evidence for immediate processing of "missing" verbs in sentence comprehension. Brain and Language 89(3). 584-592. DOI: https://doi.org/10.1016/j.bandl.2004.02.004

Kahnemuyipour, Arsalan. 2009. The syntax of sentential stress. Oxford: Oxford University Press.

Kahnemuyipour, Arsalan. 2017. Negation is low in Persian: Evidence from nominalization. Proceedings of the 2017 Annual Conference of the Canadian Linguistic Association.

Kahnemuyipour, Arsalan. 2018. Prosody. In: Anousha Sedighi \& Pouneh Shabani-Jadidi (eds.), The Oxford Handbook of Persian Linguistics, 142-158. Oxford: Oxford University Press.

Kaps, Marju. in press. Information structural effects in processing contrastive ellipsis: Eyetracking evidence from a flexible word order language. Special issue of Journal of Linguistics on experimental and corpus approaches to ellipsis.

Karimi, Simin. 2003. On object positions, specifity, and scrambling in Persian. In Simin Karimi (ed.), Word Order and Scrambling, 91-25. Blackwell Publishing. DOI: https://doi. org/10.1002/9780470758403.ch5

Karimi, Simin. 2005. A minimalist approach to scrambling: Evidence from Persian. Mouton de Gruyter. DOI: https://doi.org/10.1515/9783110199796

Karimi, Simin \& Azita H. Taleghani. 2007. Wh-movement, interpretation, and optionality in Persian. In Simin Karimi, Vida Samiian \& Wendy Wilkins (eds.), Phrasal and Clausal Architecture: Syntactic Derivation and Interpretation. In honor of Joseph E. Emonds, 167-187. John Benjamins Publishing Co. DOI: https://doi.org/10.1075/la.101.09kar

Keenan, Edward. 1971. Names, quantifiers, and the sloppy identity problem. Papers in Linguistics 4. 211-232.

Konietzko, Andrea \& Susanne Winkler. 2010. Contrastive ellipsis: Mapping between syntax and information structure. Lingua 120(6). 1436-1457. DOI: https://doi.org/10.1016/j.lingua.2008.08.009

Laka, Itziar. 1990. Negation in syntax: On the nature of functional categories and projections. Cambridge, MA: Massachusetts Institute of Technology dissertation.

Lawn, Alexandra \& Jesse A. Harris. 2017. Structural bias, cue-relevancy and similarity-based interference in Spanish sluiced sentences. Paper presented at California Meeting on Psycholinguistics (CAMP). UCLA, Los Angeles.

Lawn, Alexandra \& Jesse A. Harris. 2019. Similarity-based interference and morphological retrieval in Portuguese sluiced sentences. Poster presented at the $32^{\text {nd }}$ Annual CUNY Conference on Human Sentence Processing (CUNY). Boulder: University of Colorado.

Lenth, Russell V. 2021. Estimated marginal means, aka least-squares means. R package version 2021.1.5.4. https://github.com/rvlenth/emmeans.

Lobeck, Anne. 1995. Ellipsis: Functional Heads, Licensing, and Identification. Oxford University Press. DOI: https://doi.org/10.9793/elsj1984.16.152

Lopez, Luis. 1999. VP-ellipsis in Spanish and English and the features of Aux. Probus 11. 263-297. DOI: https://doi.org/10.1515/prbs.1999.11.2.263

Lopez, Luis. 2000. Ellipsis and discourse linking. Lingua 110. 183-213.

Merchant, Jason. 2001. The Syntax of Silence: Sluicing, Islands, and the Theory of Ellipsis. Oxford: Oxford University Press.

Merchant, Jason. 2003. Remarks on stripping. Ms., University of Chicago.

Merchant, Jason. 2004. Fragments and ellipsis. Linguistics and Philosophy 27. 661-738. DOI: https://doi. org/10.1007/s10988-005-7378-3

Merchant, Jason. 2013. Voice and ellipsis. Linguistic Inquiry 44. 77-108.

Merchant, Jason. 2019. Ellipsis: A survey of analytical approaches. In Jeroen van Craenenbroeck \& Tanja Temmerman (eds.), The Oxford handbook of ellipsis, 19-45. Oxford: Oxford University Press. DOI: https://doi.org/10.1093/oxfordhb/9780198712398.013.2

Morris, Amanda. 2008. Polarity ellipsis and negative stripping. Unpublished manuscript. https://babel.ucsc. edu/ hank/PolarityEllipsisandNegStripping.pdf.

Nakao, Chizuru. 2009. Island repair and non-repair by PF strategies. Maryland, MD: University of Maryland dissertation.

Newmeyer, Frederick, J. 1983. Grammatical theory: Its limits and its possibilities. Chicago: The University of Chicago Press.

Norcliffe, Elisabeth, Alice C. Harris \& Florian Jaeger. 2015. Cross-linguistic psycholinguistics and its critical role in theory development: early beginnings and recent advances. Language, Cognition, and Neuroscience 30(9). 1009-1032. DOI: https://doi.org/10.1080/23273798.2015.1080373

Ortega-Santos, Iván, Masaya Yoshida \& Chizuru Nakao. 2014. On ellipsis structures involving a wh-remnant and a non-wh-remnant simultaneously. Lingua 138. 55-85.

Peterson, David. 1974. Noun phrase specificity. Ann Arbor, MI: University of Michigan dissertation.

Paterson, Kevin B., Simon P. Liversedge, Ruth Filik, Barbara J. Juhasz, Sarah J. White \& Keith Rayner. 2007. Focus identification during sentence comprehension: Evidence from eye movements. The Quarterly Journal of Experimental Psychology 60. 1423-1445. DOI: https://doi. 
org/10.1080/17470210601100563

Phillips, Colin \& Dan Parker. 2014. The psycholinguistics of ellipsis. Lingua 151. 78-95. DOI: https://doi. org/10.1016/j.lingua.2013.10.003

R Core Team. 2020. R: A language and environment for statistical computing. Vienna, Austria: R Foundation for Statistical Computing. URL https://www.R-project.org/.

Rasekhi, Vahideh. 2018. Ellipsis and information structure: Evidence from Persian. Stony Brook, NY: Stony Brook University dissertation.

Rasekhi, Vahideh. 2019. On the syntax of Why-stripping in Persian. Paper presented at the Second North American Conference in Iranian Linguistics (NACIL2). Tucson: University of Arizona.

Rasekhi, Vahideh. 2020. Stripping structures with negation in Persian. In Richard Larson, Sedigheh Moradi \& Vida Samiian (eds.), Advances in Iranian Linguistics, 257-273. John Benjamins Publishing Company. DOI: https://doi.org/10.1075/cilt.351.12ras

Ross, John R. 1969. Guess who? In Robert Binnick, Alice Davison, Georgia Green \& Jerry Morgan (eds.), Papers from the 5th regional meeting of the Chicago Linguistic Society, 252-286. Chicago: Chicago Linguistic Society.

Sadat-Tehrani, Nima. 2007. The intonational grammar of Persian. Winnipeg, Canada: University of Manitoba dissertation.

Sadeghi, Ali-Ashraf. 1970. Ra dar zaban-e Farsi-e emruz (Ra in Today’s Persian). Journal of the Faculty of Literature and Humanities, 9-22. University of Tabriz.

Sag, Ivan. 1976. Deletion and logical form. Cambridge, MA: Massachusetts Institute of Technology dissertation.

Sag, Ivan \& Jorge Hankamer. 1984. Toward a theory of anaphoric processing. Linguistics and Philosophy 7(3). 325-345.

Schütze, Carson. 2011. Linguistic evidence and grammatical theory. Wiley Interdisciplinary review: Cognitive Science 2(2). 206-221. DOI: https://doi.org/10.1002/wcs. 102

Sprouse, Jon. 2018. Acceptability judgments and grammaticality, prospects and challenges. In Norbert Hornstein, Charles Yang \& Pritty Patel-Grosz (eds.), Syntactic Structures after 60 years: The impact of the Chomskyan Revolution in Linguistics, 195-224. Mouton de Gruyter. DOI: https://doi. org/10.1515/9781501506925-199

Stolterfoht, Britta, Angela D. Friederici, Kai Alter \& Anita Steube. 2007. Processing focus structure and implicit prosody during reading: Differential ERP effects. Cognition 104(3). 565-590. DOI: https://doi. org/10.1016/j.cognition.2006.08.001

Stolterfoht, Britta \& Markus Bader. 2004. Focus structure and the processing of word order variations in German. Information structure: Theoretical and empirical aspects, 259-275.

Taleghani, Azita. 2006. The interaction of modality, aspect, and negation in Persian. Tucson, Arizona: University of Arizona dissertation.

Tancredi, C. D. 1992. Deletion, deaccenting, and presupposition. Cambridge, MA: Massachusetts Institute of Technology dissertation.

Toosarvandani, Maziar. 2010. Scalar reasoning and the semantics of let alone. In Max Bane, Juan José, Bueno Holle, Thomas Grano, April Lynn Grotberg \& Yaron McNabb (eds.), Papers from the $44^{\text {th }}$ Annual Meeting of the Chicago Linguistic Society, 51-64. Chicago: Chicago Linguistic Society.

Toosarvandani, Maziar. 2013. Corrective but coordinates clauses not always but sometimes. Natural Language \& Linguistic Theory 31(3). 827-863. DOI: https://doi.org/10.1007/s11049-013-9198-4

Toosarvandani, Maziar. 2014. Contrast and the structure of discourse. Semantics \& Pragmatics 7(4). 1-57.

Toosarvandani, Maziar. 2015. Persian. In Jeroen van Craenenbroeck \& Tanja Temmerman (eds.), The Oxford handbook of ellipsis, 934-961. Oxford University Press.

Truckenbrodt, Hubert. 1995. Phonological phrases - their relation to syntax, focus, and prominence. Cambridge, MA: Massachusetts Institute of Technology dissertation.

Van Craenenbroeck, Jeroen. 2010. The syntax of ellipsis: Evidence from Dutch dialects. New York: Oxford University Press.

Van Craenenbroeck, Jeroen. 2012. How do you sluice when there is more than one CP? In Jason Merchant \& Anderson Simpson (eds.), Sluicing Cross-Linguistic Perspectives, 40-67. Oxford: Oxford University Press.

Van Craenenbroeck, Jeroen \& Tanja Temmerman (eds.). 2018. The Oxford Handbook of Ellipsis. Oxford: Oxford University Press.

Vazinpour, Nader. 1977. Dastur-e Zaban-e Farsi ('The grammar of the Persian language'). Tehran: Sepahian-e Enghelab University.

Vicente, Luis. 2006. Short negative replies in Spanish. Linguistics in the Netherlands 23(1). 199-211. DOI: https://doi.org/10.1075/avt.23.20vic

von Heusinger, Klaus \& Roya Sadeghpoor. 2020. The specificity marker $-e$ with indefinite noun phrases in Modern Colloquial Persian. In Kata Balogh, Anja Latrouite \& Robert D. Van Valin, Jr. (eds.), Nominal anchoring: Specificity, definiteness and article systems across languages, 115-147. Berlin: Language Science Press. DOI: https://doi.org/10.5281/zenodo.4049685 
Williams, Edwin. 1977. Discourse and Logical Form. Linguistic Inquiry 8(1). 101-139.

Windfuhr, Gernot L. 1987. Persian. In Bernard Comrie (ed.). The World's Major Languages, 523-546. London: Croom Helm.

Winkler, Susanne. 2018. Ellipsis and prosody. In Jereon van Craenenbroeck \& Tanja Temmerman (eds.), The Oxford Handbook of Ellipsis, 357-388. Oxford: Oxford University Press.

Wurmbrand, Susi. 2017. Stripping and Topless Complements. Linguistic Inquiry 48(2). 341-366. DOI: https://doi.org/10.1162/LING_a_00245

Yoshida, Masaya. 2018. Parsing strategies. In van Craenenbroeck, Jereon \& Temmerman, Tanja (eds.), The Oxford Handbook of Ellipsis, 253-275. Oxford: Oxford University Press. DOI: https://doi. org/10.1093/oxfordhb/9780198712398.013.20
TO CITE THIS ARTICLE: Rasekhi, Vahideh and Jesse A. Harris. 2021. Resolving ambiguous polarity stripping ellipsis structures in Persian. Glossa: a journal of general linguistics 6(1): 120. 1-31. DOI: https://doi.org/10.16995/ glossa. 5881

Submitted: 01 September 2020 Accepted: 26 June 2021 Published: 07 October 2021

COPYRIGHT:

(c) 2021 The Author(s). This is an open-access article distributed under the terms of the Creative Commons Attribution 4.0 International License (CC-BY 4.0), which permits unrestricted use, distribution, and reproduction in any medium, provided the original author and source are credited. See http:// creativecommons.org/ licenses/by/4.0/.

Glossa: a journal of general linguistics is a peer-reviewed open access journal published by Open Library of Humanities. 